Cochrane Database of Systematic Reviews

\title{
Antifibrinolytic therapy for preventing oral bleeding in people on anticoagulants undergoing minor oral surgery or dental extractions
} (Review)

Engelen ET, Schutgens REG, Mauser-Bunschoten EP, van Es RJJ, van Galen KPM

Engelen ET, Schutgens REG, Mauser-Bunschoten EP, van Es RJJ, van Galen KPM.

Antifibrinolytic therapy for preventing oral bleeding in people on anticoagulants undergoing minor oral surgery or dental extractions.

Cochrane Database of Systematic Reviews 2018, Issue 7. Art. No.: CD012293.

DOI: 10.1002/14651858.CD012293.pub2.

www.cochranelibrary.com 
TABLE OF CONTENTS

ABSTRACT 1

PLAIN LANGUAGE SUMMARY

SUMMARY OF FINDINGS

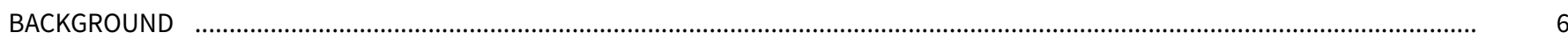

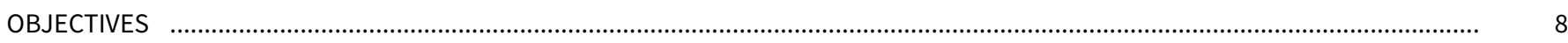

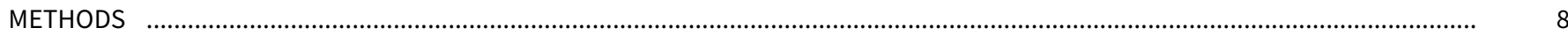

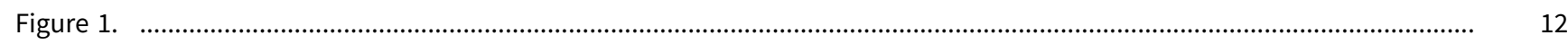

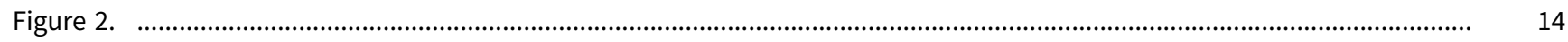

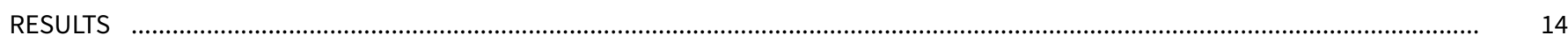

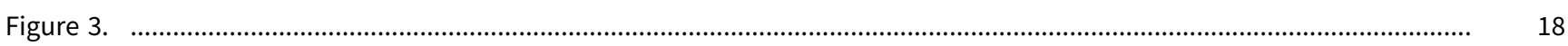

DISCUSSION

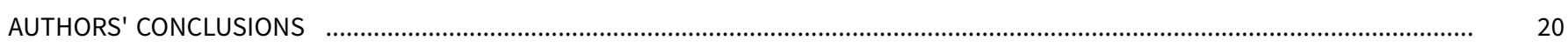

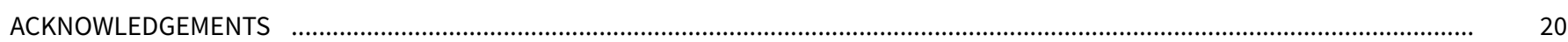

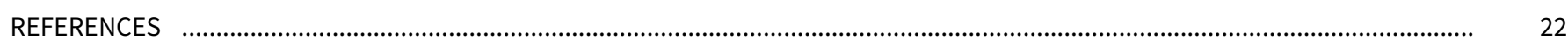

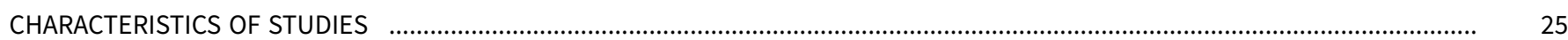

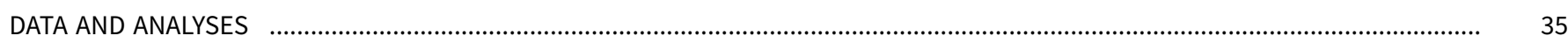

Analysis 1.1. Comparison 1 Antifibrinolytic therapy versus placebo or standard care, Outcome 1 Number of people with 36

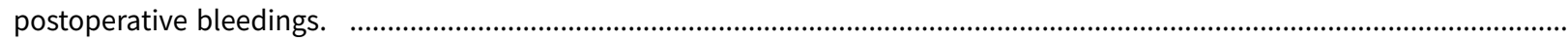

Analysis 1.2. Comparison 1 Antifibrinolytic therapy versus placebo or standard care, Outcome 2 Number of side effects requiring 36 withdrawal.

Analysis 1.3. Comparison 1 Antifibrinolytic therapy versus placebo or standard care, Outcome 3 Number of people with minor postoperative bleedings.

Analysis 1.4. Comparison 1 Antifibrinolytic therapy versus placebo or standard care, Outcome 4 Number of immediate and delayed postoperative bleedings.

Analysis 1.5. Comparison 1 Antifibrinolytic therapy versus placebo or standard care, Outcome 5 Number of people with complications other than bleeding, such as wound infection.

Analysis 1.6. Comparison 1 Antifibrinolytic therapy versus placebo or standard care, Outcome 6 Number of people with bleeding requiring transfusion of packed red blood cells.

APPENDICES

CONTRIBUTIONS OF AUTHORS

DECLARATIONS OF INTEREST

SOURCES OF SUPPORT

DIFFERENCES BETWEEN PROTOCOL AND REVIEW

INDEX TERMS 
[Intervention Review]

\section{Antifibrinolytic therapy for preventing oral bleeding in people on anticoagulants undergoing minor oral surgery or dental extractions}

Eveline T Engelen¹, Roger EG Schutgens², Evelien P Mauser-Bunschoten², Robert JJ van Es³, Karin PM van Galen²

1University Medical Centre Utrecht, Utrecht, Netherlands. 2Van Creveldkliniek / Department of Haematology, University Medical Centre Utrecht, Utrecht, Netherlands. ${ }^{3}$ Oral and Maxillofacial Surgery, University Medical Center Utrecht, Utrecht, Netherlands

Contact: Karin PM van Galen, Van Creveldkliniek / Department of Haematology, University Medical Centre Utrecht, Heidelberglaan 100, Utrecht, 3584CX, Netherlands. karinvangalen@yahoo.co.uk, K.P.M.vanGalen@umcutrecht.nl.

Editorial group: Cochrane Cystic Fibrosis and Genetic Disorders Group.

Publication status and date: New, published in Issue 7, 2018.

Citation: Engelen ET, Schutgens REG, Mauser-Bunschoten EP, van Es RJJ, van Galen KPM. Antifibrinolytic therapy for preventing oral bleeding in people on anticoagulants undergoing minor oral surgery or dental extractions. Cochrane Database of Systematic Reviews 2018, Issue 7. Art. No.: CD012293. DOI: 10.1002/14651858.CD012293.pub2.

Copyright (c) 2018 The Cochrane Collaboration. Published by John Wiley \& Sons, Ltd.

\section{A B S T R A C T}

\section{Background}

Individuals on continuous treatment with vitamin K antagonists (VKAs) or direct oral anticoagulants (DOACs) are at increased risk of bleeding complications during and after oral or dental procedures. Anticoagulant treatment is preferably continued at the same dose, since dose reduction or discontinuation of treatment is associated with an increased risk of thromboembolism. The use of haemostatic measures during or after the procedure (or both) could enable continuation of the oral anticoagulant treatment.

\section{Objectives}

We aimed to assess the efficacy of antifibrinolytic agents for preventing bleeding complications in people on oral anticoagulants undergoing minor oral surgery or dental extractions.

\section{Search methods}

We searched the Cochrane Cystic Fibrosis and Genetic Disorders Coagulopathies Trials Register, compiled from electronic database searches and handsearching of journals and conference abstract books. We also searched the reference lists of relevant articles and reviews. We searched PubMed, Embase and the Cochrane Library. Additional searches were performed using ClinicalTrials.gov, the International Clinical Trials Registry Platform (ICTRP), the CINAHL database of nursing and allied health services, the open access ProQuest dissertation database, papers and reports from the American College of Clinical Pharmacy (ACCP) and abstract books from annual scientific conferences.

Date of last search: 04 January 2018.

\section{Selection criteria}

Randomised and quasi-randomised controlled trials in people on continuous treatment with VKAs or DOACs undergoing oral or dental procedures using antifibrinolytic agents (tranexamic acid (TXA) or epsilon aminocaproic acid) to prevent perioperative bleeding compared to no intervention or usual care with or without placebo.

\section{Data collection and analysis}

Two authors independently screened the titles and abstracts of all identified articles. Full texts were obtained from potentially relevant abstracts and two authors independently assessed these for inclusion based of the selection criteria. A third author verified trial eligibility. 
Two authors independently performed data extraction and risk of bias assessments using standardized forms. The quality of the evidence was assessed using GRADE.

\section{Main results}

No eligible trials in people on continuous treatment with DOACs undergoing oral or dental procedures were identified.

Three randomised trials and one quasi-randomised trial (follow-up in all was seven days) in people on continuous treatment with VKAs were included with a total of 253 participants (mean age 60 years). Two trials published in 1989 and 1993 compared the antifibrinolytic agent TXA with placebo in people using VKAs. Two other trials were published in 1999 and 2015 and compared TXA with gelatin sponge and sutures, and dry gauze compression, respectively. In all included trials, those who were treated with VKAs had international normalised ratio (INR) values within the therapeutic range and TXA was applied locally, not systemically.

The two trials from 1989 and 1993 comparing TXA with placebo showed a statistically significant beneficial effect regarding the number of major postoperative bleeding episodes requiring intervention, with a pooled risk difference (RD) of -0.25 ( $95 \%$ confidence interval (Cl) -0.36 to -0.14 ) (128 participants) (moderate-quality evidence). For the two trials that compared TXA with either gelatin sponge and sutures or with dry gauze compression, there was no difference between the TXA and the standard care group, RD $0.02(95 \% \mathrm{Cl}-0.07$ to 0.11$)$ (125 participants) (moderate-quality evidence). The combined RD of all included trials was $-0.13(95 \% \mathrm{Cl}-0.30$ to 0.05$)$ (moderate-quality evidence). There were no side effects of antifibrinolytic therapy that required treatment withdrawal (128 participants) (moderate-quality evidence). Despite heterogeneity between trials with respect to the different haemostatic measures used in the control groups, the trials were comparable regarding design and baseline participant characteristics.

Overall, we considered the risk of bias to be low in the trials comparing TXA with placebo and moderate in the trials comparing TXA with alternative haemostatic measures.

\section{Authors' conclusions}

Based on the results of this Cochrane Review, there seems to be a beneficial effect of locally applied TXA in preventing oral bleeding in people on continuous treatment with VKAs undergoing minor oral surgery or dental extractions. However, the small number of identified randomised controlled trials, the relatively small number of participants included in the trials and the differences in standard therapy and treatment regimens between trials, do not allow us to conclude definite efficacy of antifibrinolytic therapy in this population.

We were unable to identify any eligible trials in people on continuous treatment with DOACs undergoing oral or dental procedures. Therefore, a beneficial effect of antifibrinolytic therapy can currently only be assumed based on data from the people using VKAs.

\section{PLAIN LANGUAGE SUMMARY}

\section{Drugs that prevent oral bleeding in people using oral anticoagulants undergoing minor oral surgery or dental extractions}

\section{Review question}

We reviewed the evidence about whether antifibrinolytic medicine (drugs that prevent breakdown of a blood clot), such as tranexamic acid or epsilon aminocaproic acid, can prevent oral bleeding after minor oral surgery or dental extractions in people using oral anticoagulants (blood thinners that are taken by mouth) without interruption during the procedure.

\section{Background}

People on continuous oral anticoagulant treatment are at an increased risk of bleeding complications during and after oral surgery or dental extractions. There are two types of oral anticoagulant treatment: vitamin K antagonists (VKAs) (e.g. warfarin and coumarin) and direct oral anticoagulants (DOACs) (e.g. dabigatran, rivaroxaban, apixaban, edoxaban). DOACs are becoming an increasingly popular alternative for VKAs, traditionally used for preventing blood clotting in people at risk of thrombosis. The number of bleeds and the severity of each bleed depend on medication-related factors (such as the degree of anticoagulation, measured by the international normalised ratio (INR)), surgery-related factors (such as the size of the wound or the number of roots extracted), as well as patient-related factors (such as inflammation of the gums or blood vessel diseases). The INR level is important to determine how well the anticoagulant treatment is preventing blood clots. Within the desired range of the INR level, a person has both the least risk of blood clotting complications and the least risk of excessive bleeding. In routine practice antifibrinolytic medicine is often used before, during and after minor oral surgery or dental extractions for people using oral anticoagulants. The question is whether there is reliable scientific evidence for this practice.

\section{Search date}

The evidence is current to: 04 January 2018.

\section{Study characteristics}

We did not find any trials of antifibrinolytic medicine for preventing bleeding after minor oral surgery or dental extractions in people using DOACs. This review includes four trials (253 participants) in people continuously treated with VKAs during minor oral surgery or dental

Antifibrinolytic therapy for preventing oral bleeding in people on anticoagulants undergoing minor oral surgery or dental extractions 
extractions. The earliest included trial was published in 1989 and the most recent one in 2015. The mean age of all participants was 60 years. The follow-up time in all trials was seven days.

\section{Key results}

Overall, the included trials showed a reduction in the number of bleeds after dental extraction when using tranexamic acid solution in the mouth. Combining the results of the separate trials it appeared that antifibrinolytic medication reduces the bleeding rate after dental extractions by $25 \%$ when compared to placebo ('dummy' treatment). However, there was no difference in bleeding rate between people treated with tranexamic acid and those treated with standard care (e.g. gauze compression or stitches). Side effects of the antifibrinolytic medication rarely occurred and did not lead to individuals discontinuing tranexamic acid treatment.

No evidence was found for people being treated with DOACs. It could, however, be argued that, if antifibrinolytic medicine is effective in people on continuous treatment with VKAs, it might also work for people receiving other comparable anticoagulant drugs.

\section{Quality of evidence}

In relation to the review's two primary outcomes of number of postoperative bleeds and side effects of therapy, we judged there to be moderate-quality evidence.

In the two trials comparing tranexamic acid with placebo, the risk of bias, in relation to trial design, was considered to be low, in the two trials comparing tranexamic acid to standard care (gelatin sponge and sutures; or dry gauze compression) the risk of bias was considered to be moderate. This was mainly due to the lack of blinding (a way of making sure that the people involved in the trial do not know which trial arm they are assigned to) and inadequate allocation concealment (using the play of chance to assign participants to comparison groups to prevent selection bias) in two of these trials. There were differences between the trials with regards to different standard care treatments. 


\section{SUMMARY OF FINDINGS}

\section{Summary of findings for the main comparison.}

Antifibrinolytic therapy compared with placebo, usual care or no intervention for preventing oral bleeding in patientson continuous oral anticoagulant treatment

Patient or population: people on continuous oral anticoagulant treatment

Settings: hospitals, dental centers

Intervention: antifibrinolytic therapy (tranexamic acid (TXA) OR epsilon aminocaproic acid (EACA))

Comparison: control (placebo, or no intervention or usual care with or without placebo)

\begin{tabular}{|c|c|c|c|c|c|c|}
\hline \multirow[t]{2}{*}{ Outcomes } & \multicolumn{2}{|c|}{ Anticipated absolute effects ${ }^{\star}(95 \% \mathrm{CI})$} & \multirow{2}{*}{$\begin{array}{l}\text { Absolute effect } \\
\text { (RD and 95\% } \\
\text { CI) }\end{array}$} & \multirow{2}{*}{$\begin{array}{l}\text { No. of partici- } \\
\text { pants } \\
\text { (studies) }\end{array}$} & \multirow{2}{*}{$\begin{array}{l}\text { Quality of the } \\
\text { evidence } \\
\text { (GRADE) }\end{array}$} & \multirow[t]{2}{*}{ Comments } \\
\hline & Risk with controla & $\begin{array}{l}\text { Risk with antifibrinolytic } \\
\text { therapy }\end{array}$ & & & & \\
\hline Postoperative bleedings requiring & \multicolumn{2}{|l|}{ Study population } & \multirow{2}{*}{$\begin{array}{l}\text { RD }-\mathbf{0 . 2 5} \\
(-0.36 \text { to }-0.14)\end{array}$} & \multirow{2}{*}{$\begin{array}{l}128 \\
(2 \mathrm{RCTs})\end{array}$} & \multirow{2}{*}{$\begin{array}{l}\oplus \oplus \oplus \ominus \\
\text { MODERATEC }\end{array}$} & \\
\hline $\begin{array}{l}\text { Control group: placeboa } \\
\text { Follow-up: } 7 \text { days }\end{array}$ & 277 per 1000 & $\begin{array}{l}69 \text { fewer per } 1000 \\
(100 \text { fewer to } 4 \text { fewer per } 1000)\end{array}$ & & & & \\
\hline Postoperative bleedings requiring & \multicolumn{2}{|l|}{ Study population } & \multirow{2}{*}{$\begin{array}{l}\text { RD } 0.02 \\
(-0.07 \text { to } 0.11)\end{array}$} & \multirow{2}{*}{$\begin{array}{l}125 \\
(2 \text { RCTs) }\end{array}$} & \multirow{2}{*}{$\begin{array}{l}\oplus \oplus \oplus \ominus \\
\text { MODERATEC }\end{array}$} & \\
\hline $\begin{array}{l}\text { Control group: standard Carea } \\
\text { Follow-up: } 7 \text { days }\end{array}$ & 630 per $10,000^{b}$ & $\begin{array}{l}1 \text { more per } 10,000^{b} \\
\text { ( } 4 \text { fewer to } 7 \text { more per } 10,000 \text { ) }\end{array}$ & & & & \\
\hline Side effects or other adverse & \multicolumn{2}{|l|}{ Study population } & \multirow{2}{*}{$\begin{array}{l}\text { RD 0.00, } \\
\text { (-0.04 to } 0.04)\end{array}$} & \multirow{2}{*}{$\begin{array}{l}128 \\
(2 \mathrm{RCTs})\end{array}$} & \multirow{2}{*}{$\begin{array}{l}\oplus \oplus \oplus \ominus \\
\text { MODERATEC }\end{array}$} & \\
\hline $\begin{array}{l}\text { Control group: placeboa } \\
\text { Follow-up: } 7 \text { days }\end{array}$ & $\begin{array}{l}\text { No adverse events } \\
\text { requiring with- } \\
\text { drawal occurred in } \\
\text { the placebo group }\end{array}$ & $\begin{array}{l}\text { No adverse events requiring } \\
\text { withdrawal occurred in the an- } \\
\text { tifibrinolytic therapy group }\end{array}$ & & & & \\
\hline
\end{tabular}

${ }^{\star}$ The risk in the control group is calculated at the event rate within the control group. The risk in the intervention group (and its $95 \%$ confidence interval) is based on the assumed risk in the comparison group and the absolute effect of the intervention (and its $95 \% \mathrm{Cl}$ ).

Cl: confidence interval; $\mathbf{R D}$ : risk difference

\section{GRADE Working Group grades of evidence}

High quality: we are very confident that the true effect lies close to that of the estimate of the effect 
Moderate quality: we are moderately confident in the effect estimate: The true effect is likely to be close to the estimate of the effect, but there is a possibility that it is substantially different

Low quality: our confidence in the effect estimate is limited: The true effect may be substantially different from the estimate of the effect

Very low quality: we have very little confidence in the effect estimate: The true effect is likely to be substantially different from the estimate of effect

a. Results for control groups (placebo and standard care) analysed separately are presented due to high levels of heterogeneity in analysis where control groups are combined $\left(I^{2}=80 \%\right)$

b. Risks of 'Postoperative bleedings requiring intervention' within the standard care group expressed per 10,000 due to small numbers of events occurring in both groups

c. The evidence is downgraded once to moderate due to relatively small sample sizes (imprecision) 


\section{B A C K G R O U N D}

\section{Description of the condition}

Minor oral surgery and dental extractions are frequently performed procedures. Individuals on continuous treatment with a vitamin $\mathrm{K}$ antagonist (VKA) or direct oral anticoagulants (DOACs) are at an increased risk of bleeding complications during and after these type of procedures. Minor oral surgery was defined as surgery involving the teeth, palate, floor of the mouth, tongue and other soft tissues in the oropharyngeal cavity. The efficacy of antifibrinolytic agents in people with inherited bleeding disorders undergoing minor oral surgery or dental extractions is presented in a separate Cochrane Review (van Galen 2015).

\section{Vitamin $\mathrm{K}$ antagonists}

Currently, VKAs are the most commonly used anticoagulant drugs; they act by inhibiting the carboxylation of the vitamin K-dependent coagulation factors II (prothrombin), VII, IX, and X, and also inhibit proteins C and S (Mega 2015). They have proven effective for preventing and treating thrombosis in a number of cardiovascular conditions, such as atrial fibrillation, venous thromboembolism and prosthetic heart valves (Douketis 2012).

Therapeutic levels of VKAs are monitored by measuring the international normalised ratio (INR), which should be held within a narrow therapeutic range to prevent thromboembolism without introducing bleeding complications (Douketis 2012; Perry 2007; Randall 2007; Sime 2015). This can be challenging due to the variability in dose response among individuals and due to interactions with other drugs and food and therefore requires frequent laboratory monitoring (Ansell 2004). After establishing the individual risk pattern, individuals are assigned to either a low- or a high-intensity INR therapeutic range. Internationally, the low- and high-intensity therapeutic ranges are defined as INR levels between 2.0 and 3.0 and between 2.5 and 3.5, respectively (Ansell 2004).

An INR level above or below the threshold is associated with an increased bleeding or thromboembolic risk, respectively. In addition, the withdrawal of anticoagulant treatment may induce rebound hypercoagulably due to excessive thrombin generation (Ascani 1999; Cundiff 2008; Palareti 1996). This would increase the risk of thromboembolic events even further after VKA interruption (Ascani 1999; Cundiff 2008; Palareti 1996). A metaanalysis published in 2016 including only randomised controlled trials (RCTs) or controlled clinical trials showed an incidence of postoperative bleeding of $11 \%$ in people on continuous oral anticoagulant treatment undergoing dental extractions (Yang 2016).

In an educational letter, Wahl was one of the first dentists that drew attention to the risk of embolic complications following discontinuation of continuous anticoagulant treatment for dental surgery (Wahl 2000). He selected 17 articles on anticoagulant therapy for different ailments in various journals and encountered five complications he alleged to be (but were in retrospect not all necessarily so) related to anticoagulant withdrawal for dental extractions.

\section{Direct oral anticoagulants}

DOACs were developed as alternatives to VKAs. Major advantages of DOACs include fewer food and drug interactions, a short half life and fixed-dose anticoagulation without the need for periodic monitoring (Hussain 2017). The DOACs act by directly inhibiting activated clotting factors. Currently available DOACs include dabigatran, rivaroxaban, edoxaban and apixaban. Dabigatran inhibits factor lla (thrombin), and rivaroxaban, endoxaban and apixaban inhibit factor Xa (Adcock 2015). A recently published retrospective observational study compared 52 oral procedures in individuals under continued anticoagulant treatment with rivaroxaban ( $20 \mathrm{mg}$ per day) with 285 oral procedures in individuals without any anticoagulant or antiplatelet treatment (Hanken 2016). The number of postoperative bleeding complications was significantly higher in the rivaroxaban group compared to the control group, with bleeding complications in $11.5 \%$ and $0.7 \%$ of the individuals respectively. All bleeding complications were manageable with local measures.

\section{Perioperative management in oral or dental procedures}

Fibrinolytic activity is particularly high in oral mucosa due to the fibrinolytic activity of saliva and the local production of tissue plasminogen activator (t-PA) which converts plasminogen into plasmin causing fibrin degradation (Sindet-Pedersen 1990). The use of antifibrinolytic agents could therefore enable the continuation of oral anticoagulant treatment in patients undergoing oral or dental procedures, while limiting the risk of bleeding. It is especially interesting to note that for more than two hours after mouth rinsing with tranexamic acid (TXA) mouthwash, TXA concentrations in saliva remain at a therapeutic level, while after oral administration, TXA concentrations in saliva remain undetectable (Sindet-Pedersen 1990).

Traditionally, the perioperative management of oral and dental procedures in anticoagulated individuals included interruption or dose reduction of anticoagulant treatment to prevent bleeding complications. Recent guidelines recommend to either continue VKAs with an additional 'haemostatic intervention' or to stop VKAs two to three days before the procedure, depending on the thromboembolic and bleeding risks of the individual and the type of surgical procedure (Douketis 2012; Perry 2007; Randall 2007; Sime 2015). Evidence for both treatment regimens is scarce. According to the aforementioned guidelines, haemostatic interventions include, for example, antifibrinolytic agents (e.g. TXA mouthwash), sutures, oxidized cellulose or collagen sponges (Douketis 2012; Perry 2007; Randall 2007; Sime 2015).

Guidelines present the same recommendations for DOACs as for VKAs. These include either continuing treatment with local haemostatic measures or discontinuing treatment before the procedure, after carefully weighing the bleeding risk versus the thromboembolic risk. In general, treatment with DOACs should be discontinued in procedures with a moderate or high bleeding risk, and treatment may be continued in procedures with a low bleeding risk (Heidbüchel 2012; Heidbüchel 2013; Heidbuchel 2015; Randall 2015). Dental procedures that are associated with a low bleeding risk include the extraction of one to three teeth, periodontal surgery, incision of an abscess and implant positioning (Heidbuchel 2015).

Considering the risk of thromboembolism after the withdrawal of anticoagulant treatment in the perioperative phase, it is important to continue this treatment in certain patients at high thrombotic risk and to search for additional methods or agents to prevent bleeding complications. Antifibrinolytic therapy is 
a relatively cheap, safe and potentially effective therapy for preventing bleeding complications in oral and dental procedures (Forbes 1972; McCormack 2012; Olsen 2016; Sindet-Pedersen 1989). Current guidelines recommend the use of additional haemostatic interventions in patients on continuous oral anticoagulant treatment undergoing oral and dental procedures to minimise the bleeding risk (Douketis 2012). The guidelines do not state clearly which additional haemostatic intervention should be preferred. Although most dental procedures are associated with a low bleeding risk, the bleeding risk postoperatively is still significantly higher than in people not using anticoagulants (Hanken 2016).

\section{Description of the intervention}

The main precautions used to prevent perioperative bleeding in individuals on continuous anticoagulant treatment undergoing oral or dental procedures are haemostatic interventions, including the previously mentioned antifibrinolytic agents, sutures, oxidized cellulose and collagen sponges (Douketis 2012; Perry 2007; Randall 2007). The most commonly used antifibrinolytic agents are TXA and epsilon aminocaproic acid (EACA). Antifibrinolytics prevent degradation of the fibrin clot which supports blood clotting. Antifibrinolytic agents can be administered topically as a mouthwash or systemically as oral or intravenous formulations (see table below). There are currently no guidelines available on when antifibrinolytic treatment should be started and for how long treatment should be continued. In general, if TXA is used, it is given before the dental procedure and three- to four-times daily for one to seven days after the procedure (Douketis 2012). In people with renal insufficiency, a dose reduction is necessary to ensure renal clearance. Antifibrinolytic agents are contraindicated if there is active venous or arterial thromboembolic disease.

\section{Dosing of antifibrinolytic agents}

\begin{tabular}{lll}
\hline $\begin{array}{l}\text { Antifibrinolytic Available strength Dose (adults) Dose (children) } \\
\text { agent }\end{array}$ &
\end{tabular}

\begin{tabular}{|c|c|c|c|}
\hline TXA mouthwash & $50 \mathrm{mg} / \mathrm{mL}$ & $10 \mathrm{~mL}$, 4-times-daily & $\begin{array}{l}\geq 1 \text { year: } 20 \mathrm{mg} / \mathrm{kg} \text { body weight/day in } 2 \text { to } 3 \text { dos- } \\
\text { es per day }\end{array}$ \\
\hline IV TXA & $\begin{array}{l}100 \mathrm{mg} / \mathrm{mL} \text { slowly } \\
\text { IV }(1 \mathrm{~mL} / \mathrm{min})\end{array}$ & $\begin{array}{l}500 \mathrm{mg} \text { to } 1000 \mathrm{mg} \text {, 2- to 3-times- } \\
\text { daily }\end{array}$ & $\begin{array}{l}\geq 1 \text { year: } 20 \mathrm{mg} / \mathrm{kg} \text { body weight/day in } 2 \text { to } 3 \text { dos- } \\
\text { es per day }\end{array}$ \\
\hline TXA tablets & $500 \mathrm{mg}$ & $1 \mathrm{~g}$ to $1.5 \mathrm{~g}, 2$ - to 3-times-daily & $\begin{array}{l}\geq 1 \text { year: } 20 \mathrm{mg} / \mathrm{kg} \text { body weight/day in } 2 \text { to } 3 \text { dos- } \\
\text { es per day }\end{array}$ \\
\hline IV EACA & $250 \mathrm{mg} / \mathrm{mL}$ & $\begin{array}{l}\text { Starting dose } 4 \mathrm{~g} \text { to } 5 \mathrm{~g} \text { slowly IV } \\
\text { (more than } 1 \text { hour), followed by } \\
\text { continuous infusion of } 1 \mathrm{~g} / \text { hour }\end{array}$ & $\begin{array}{l}100 \mathrm{mg} / \mathrm{kg} \text { or } 3 \mathrm{~g} / \mathrm{m}^{2} \text { slowly IV during the first } \\
\text { hour, followed by continuous infusion } 33.3 \mathrm{mg} / \\
\mathrm{kg} / \text { hour or } 1 \mathrm{~g} / \mathrm{m}^{2} / \text { hour }\end{array}$ \\
\hline EACA tablets & $\begin{array}{l}500 \mathrm{mg} \text { and } 1000 \\
\mathrm{mg}\end{array}$ & $\begin{array}{l}\text { Starting dose } 4 \mathrm{~g} \text { to } 5 \mathrm{~g} \text {, followed } \\
\text { by } 1 \text { to } 1.25 \mathrm{~g} / \text { hour. Maximum } \\
\text { dose } 24 \mathrm{~g} \text { per } 24 \text { hours }\end{array}$ & $\begin{array}{l}\text { starting } 100 \mathrm{mg} / \mathrm{kg} \text {, followed by } 3 \mathrm{~g} / \mathrm{m}^{2} \text { during the } \\
\text { first hour, followed by } 33.3 \mathrm{mg} / \mathrm{kg} \text { or } 1 \mathrm{~g} / \mathrm{m}^{2} \text { every } \\
\text { hour, maximum } 18 \mathrm{~g} / \mathrm{m}^{2}(600 \mathrm{mg} / \mathrm{kg}) \text { in } 24 \text { hours }\end{array}$ \\
\hline
\end{tabular}

Abbreviations: EACA: epsilon aminocaproic acid; IV: intravenous; TXA: tranexamic acid.

\section{How the intervention might work}

The antifibrinolytic agents TXA and EACA act by binding reversibly to plasminogen and blocking the interaction of plasminogen with fibrin, thereby preventing degradation of the fibrin clot. The agent TXA is more potent than EACA (Pell 1973). Fibrinolytic activity is particularly high in oral mucosa due to the fibrinolytic activity of saliva and local t-PA production (Sindet-Pedersen 1990). Therefore, the inhibition of fibrinolysis with antifibrinolytic agents is a rational approach for limiting oral bleeding after surgery in patients using oral anticoagulants. A trial conducted in 1987 showed that, after oral administration, the mean plasma concentration of TXA reached its maximum after 120 minutes at approximately 7 micrograms $(\mu \mathrm{g}) / \mathrm{mL}$, whereas none of the saliva samples contained TXA at detectable levels. After mouth rinsing, the plasma concentrations remained below $2 \mu \mathrm{g} / \mathrm{mL}$, whereas the concentrations found in saliva initially were very high (after 30 minutes mean concentration above $200 \mu \mathrm{g} / \mathrm{mL}$ ) and remained at a therapeutic level for more than two hours (Sindet-Pedersen 1987).

\section{Why it is important to do this review}

The aim of this review is to analyse the evidence for the use of antifibrinolytic agents in individuals on continuous VKA or DOAC treatment undergoing oral or dental procedures. Given their low cost, high tolerability, effectiveness and safety, antifibrinolytic agents are an attractive alternative to prevent postoperative bleeding in oral surgery. If this review finds sufficient scientific evidence to support the use of antifibrinolytic agents in patients on continuous oral anticoagulant treatment undergoing oral and dental procedures, this treatment could become the standard therapeutic approach. Antifibrinolytic therapy may enable continuation of anticoagulant treatment perioperatively and it therefore may prevent the need for discontinuation or dose reduction of anticoagulant drugs, reducing the thromboembolic risk with potentially life-threatening outcomes in the high-risk groups. 


\section{O B JECTIVES}

We aimed to assess the efficacy of antifibrinolytic agents for preventing bleeding complications in people on oral anticoagulants undergoing minor oral surgery or dental extractions.

\section{METHOD S}

\section{Criteria for considering studies for this review}

\section{Types of studies}

RCTs or quasi-RCTs in people on anticoagulant treatment undergoing oral or dental procedures.

\section{Types of participants}

People of all ages on continuous VKA or DOAC treatment undergoing oral or dental procedures. We defined the therapeutic range of VKAs as an INR level between 2.0 and 4.0. Oral and dental procedures included surgery related to teeth (tooth extraction including third molar removal and implant placement), periodontal tissues, or soft tissues in the oral cavity. Individuals using acetylsalicylic acid were not included in this review, as the general approach for minor dental procedures in these individuals already includes continuation of acetylsalicylic acid without an increased risk of excessive bleeding (Douketis 2012; Zhao 2015).

\section{Types of interventions}

\section{Intervention}

The use of antifibrinolytic agents (TXA or EACA) to prevent perioperative bleeding in people on oral anticoagulant medication undergoing oral or dental procedures at any dose, mode of delivery (topical, oral or intravenous), frequency and duration of administration, started before, during or immediately after the intervention.

\section{Comparator interventions}

Placebo or no intervention or usual care with or without placebo. Usual care in this population included mainly surgical intraoperative measures (e.g. mucosal flap placement, gauze compression, sutures). In order to reliably assess the efficacy of antifibrinolytic therapy, comparison groups receiving additional haemostatic agents other than antifibrinolytic medication (e.g. fibrin glue) were excluded from the analysis.

\section{Types of outcome measures}

\section{Primary outcomes}

1. Number of participants with major postoperative bleeding episodes (defined as postoperative bleeding episodes requiring intervention*)

2. Side effects or other adverse events*

*Postoperative bleeding episodes include immediate postoperative bleeds (defined as bleeding within 24 hours after surgery), as well as delayed postoperative bleeds (defined as bleeding 24 hours to 10 days after surgery) and both clinically relevant (non-major) bleeding requiring medical attention (e.g. wound dressing or additional sutures) and major bleeding requiring transfusion of packed red blood cells. Intervention is defined as any additional treatment or medical attention needed in addition to usual care to halt postoperative bleeding up to 10 days post surgery.

** Side effects of antifibrinolytic agents are mainly gastro-intestinal and will only be considered clinically relevant if they lead to discontinuation or change of therapy.

\section{Secondary outcomes}

1. Number of minor postoperative bleeding episodes (defined as self-limiting, usually with local pressure, that does not require medical attention)

2. Number of immediate (less than 24 hours) and delayed (24 hours to 10 days) postoperative bleeding episodes requiring intervention

3. Any postoperative complication except bleeding (e.g. wound infection)

4. Change in haemoglobin level from baseline

5. Major bleeding, requiring transfusion of packed red blood cells

6. Bleeding duration (minutes, all types of bleeding minor and major)

7. Amount of postoperative blood loss $(\mathrm{mL})$

8. Number of thromboembolic complications

\section{Search methods for identification of studies}

We searched for all relevant published and unpublished trials without restrictions on language, year or publication status.

\section{Electronic searches}

The Cochrane Cystic Fibrosis and Genetic Disorders Group's Information Specialist conducted a systematic search of the Group's Coagulopathies Fibrosis Trials Register for relevant trials using the following term: antifibrinolytics.

The Coagulopathies Trials Register is compiled from electronic searches of the Cochrane Central Register of Controlled Trials (CENTRAL) (updated each new issue of the Cochrane Library) and weekly searches of MEDLINE and the prospective handsearching of one journal - Haemophilia. Unpublished work is identified by searching the abstract books of major conferences: the European Haematology Association conference; the American Society of Hematology conference; the British Society for Haematology Annual Scientific Meeting; the Congress of the World Federation of Hemophilia; the European Association for Haemophilia and Allied Disorders, the American Society of Gene and Cell Therapy and the International Society on Thrombosis and Haemostasis. For full details of all searching activities for the register, please see the relevant section of the Cochrane Cystic Fibrosis and Genetic Disorders Group's website.

Date of the most recent search of the Group's Coagulopathies Trials Register: 25 February 2018.

We searched the following databases and trial registries:

- Cochrane Central Register of Controlled Trials (CENTRAL, 2018) and Cochrane Database of Systematic Reviews (CDSR) in the Cochrane Library (http://www.cochranelibrary.com/; searched 4 January 2018);

- PubMed (https://www.ncbi.nlm.nih.gov/pubmed/; 1946 to 4 January 2018);

Antifibrinolytic therapy for preventing oral bleeding in people on anticoagulants undergoing minor oral surgery or dental extractions 
- Embase Platform (www.embase.com; 1947 to 4 January 2018);

- CINAHL Platform EBSCO (Cumulative Index to Nursing and Allied Health Literature; 1937 to 4 January 2018);

- PQDT Open (https://pqdtopen.proquest.com/search.html; searched 4 January 2018);

- US National Institutes of Health Ongoing Trials Register Clinicaltrials.gov (www.clinicaltrials.gov; searched 4 January 2018);

- World Health Organization International Clinical Trials Registry Platform (WHO ICTRP) (apps.who.int/trialsearch; searched 4 January 2018).

For details of our search strategies, please see Appendix 1.

\section{Additional search}

We also electronically searched the following online meeting abstract books:

- American College of Clinical Pharmacy Annual Meeting (ACCP; www.accp.com/meetings/abstracts.aspx searched 1999 to 2018);

- Annual Scientific Meeting of the International Society for Thrombosis and Haemostasis (www.isth.org/?PastMeetings searched 1950 to 2018);

- European Haematology Association Annual Congress (ehaweb.org/congress/previous-congresses/ searched 1994 to 2018);

- American Society of Hematology Annual Meeting (www.hematology.org/Annual-Meeting/Archive.aspx searched 2014 to 2018);

- British Society for Haematology Annual Scientific Meeting (www.b-s-h.org.uk/search 1960 to 2018)

For full details, please see Appendix 2.

\section{Searching other resources}

We checked the bibliographies of included trials and any relevant systematic reviews identified for further references to relevant trials.

\section{Data collection and analysis}

\section{Selection of studies}

Two authors (EE content area expert, KG content area expert and supervising author) independently screened titles and abstracts of all articles obtained through the searches and identified abstracts of trials that appeared to be potentially relevant. Full texts were obtained for potentially relevant abstracts and two authors (EE, KG) independently assessed these for inclusion based on the previously described selection criteria. A third author (RS) verified trial eligibility. We used a separate data collection form for assessing trial eligibility. We attempted to identify multiple reports of the same trial by comparing authors of the reports, trial dates, trial durations, number of participants, details on the interventions and location and setting of the reported trials. If we had identified multiple reports on one or more trials, we would have linked these together. A third author (RS content area expert, methodologist) verified the assessment of trials identified for inclusion. We resolved any disagreement by discussion between the three authors (EE, KG, RS). When necessary, the surgeon (RE) was involved in the discussion. Duplicate records of the same reports were removed using reference manager software (RefMan ${ }^{\circledR}$ 2010). We recorded the articles retrieved from the searches of the databases in the Review Manager (RevMan) software (RevMan 2014). We listed excluded trials, except the those which clearly failed to fulfil the selection criteria of this review, and we stated the primary reason for exclusion (Characteristics of excluded studies).

\section{Data extraction and management}

Two authors (EE, KG) independently extracted data from published reports using a data extraction form containing the characteristics of the included trials and trial participants, all outcome measures and a risk of bias table. We prepared the data extraction form using the general template and a Cochrane checklist of items to consider in data collection or data extraction (Higgins 2011a), which was authorised by all authors. A third author verified the data extraction of trials identified for inclusion (RS). There were no differences in data extraction between the authors (EE, KG, RS). It was not necessary to request further information from the original authors to clarify data.

\section{Assessment of risk of bias in included studies}

We assessed the methodological quality of the included trials by using a risk of bias table that included judgements of the adequacy of the sequence generation (selection bias), allocation concealment (selection bias), blinding of the outcome assessments (detection bias), incomplete outcome data (attrition bias), selective outcome reporting (reporting bias) and other potential sources of bias (Higgins 2011a). Two authors (EE, KG) independently completed this table for each included trial. We resolved any disagreements by discussion between the three authors (EE, KG, RS). We rated the risk of bias for each domain as low, unclear or high and summarized this information in a 'risk of bias' plot.

\section{Measures of treatment effect}

The treatment effect is the proportion of participants in the intervention group with postoperative bleedings needing treatment (immediate as well as delayed postoperative bleedings were combined), compared to those in the control group. For metaanalysis, we expressed this treatment effect as a risk difference (RD) with corresponding 95\% confidence intervals (Cls). We converted this measure to a number-needed-to-treat (NNT), after calculating the RD between the two groups. The NNT is useful for better interpretation of the results of our meta-analysis.

Formula: NNT = $1 /$ RD.

When individual participants experienced more than one event (e.g. postoperative bleeding needing intervention, side effects or adverse events), we used the number participants (rather than the number of events) in the analysis.

The measures of treatment effect for the other outcomes is the proportion of participants in the intervention group with an adverse event or one of the secondary outcomes compared to those in the control group. For meta-analysis, we converted the data to $\mathrm{RD}$ values and we presented these with corresponding $95 \% \mathrm{Cls}$.

\section{Unit of analysis issues}

We included trials with non-standard randomised controlled designs, since these trial designs may feasibly answer the research 
question. Including data from such trials could also increase the power for meta-analysis.

\section{Multiple randomisation}

Participants may have an indication for multiple, identical procedures (dental or oral) within a certain trial period. Participants may be randomised on multiple occasions in a trial due to revisits for a similar dental or oral procedure. We accounted for this issue by using the number of participants with bleeding requiring intervention as the unit of analysis in all included trials. It was not possible to extract individual patient data from the included trials to apply multilevel analysis.

\section{Studies with multiple treatment groups}

If included clinical trials randomised participants to one of several intervention groups, we planned to only include the groups where the intervention consisted of the administration of antifibrinolytic agents to prevent bleeding in oral surgery and the comparison groups were placebo, no intervention or usual care (with or without placebo) in the meta-analysis. We aimed to use the same measure of treatment effect as in the included parallel group trials. If, for future updates of this review, trials of this design meet the inclusion criteria, we plan to present the effect measure separately in the meta-analysis if more than two groups are relevant with regard to differences in the administration of antifibrinolytic agents, using a portional part of the comparison group, to allow for any subgroup analyses (Higgins 2011b).

\section{Cluster-randomised trials}

If we include cluster-randomised trials in future updates, we plan to pay special attention to the possibility of: recruitment bias; baseline imbalances; loss of clusters; incorrect analysis; herd effect; and contamination (Higgins 2011c). In the meta-analysis we plan to use the same treatment effect measure as in the included parallel group trials if the original analysis properly accounts for the cluster design, based for example on a multilevel model or generalised estimating equations (GEEs). We will seek statistical advice if needed.

\section{Dealing with missing data}

Possible sources of missing data are: missing outcomes; selective or incomplete reporting; and lack of intention-to-treat (ITT) analysis. It was not necessary to contact original investigators to request missing data.

\section{Assessment of heterogeneity}

Differences were expected in the specific interventions and participant characteristics. These differences give rise to clinical heterogeneity between the included trials. To assess the heterogeneity we considered a visual inspection of the forest plot to see whether Cls overlap. In addition, significant statistical heterogeneity arises from methodological differences between trials (Deeks 2011). To quantify inconsistency between trials, we planned to calculate the $\mathrm{I}^{2}$ statistic to describe the percentage of the variability in effect estimates that is due to heterogeneity rather than sampling error (chance) (Higgins 2003).

The interpretation of the $I^{2}$ values was as follows (Higgins 2003):

- $0 \%$ to $40 \%$ indicates unimportant levels of heterogeneity;
- $30 \%$ to $60 \%$ indicates moderate heterogeneity;

- $50 \%$ to $90 \%$ indicates substantial heterogeneity;

- $75 \%$ to $100 \%$ indicates considerable heterogeneity.

\section{Assessment of reporting biases}

To address reporting bias, we designed the literature searches to be as comprehensive as possible so as to prevent missing any potentially eligible trials. We also searched the trial registration database (www.clinicaltrials.gov) for this purpose. We did not construct a funnel plot as not enough trials could be included (less than 10). We addressed the potential impact of reporting bias on the findings in the 'Discussion' section of our final review (Higgins 2011b).

\section{Data synthesis}

We assumed that included trials use different outcome definitions of postoperative bleeding. We recorded the number of postoperative bleedings needing intervention. This outcome measure was used for meta-analysis. We combined all types of interventions with antifibrinolytic agents. We used a randomeffects model for the meta-analyses. We made this decision based on expected different outcome measures, differences in the administration of antifibrinolytic agents and the use of cointerventions. We summarized the results of the review in a 'Summary of findings' table (Summary of findings for the main comparison).

\section{Subgroup analysis and investigation of heterogeneity}

Given that we included only four trials with relatively low participant numbers, we were not able to undertake the planned subgroup meta-analyses (Deeks 2011). We reported results on these subgroups as described within the trials, if available.

1. Antifibrinolytic agents used: TXA versus EACA

2. Administration form of antifibrinolytic agents: topical versus systemic

3. Different outcome definitions of perioperative bleeding: clinically significant versus minor versus major postoperative bleedings; and immediate versus delayed postoperative bleedings

4. INR levels within the therapeutic range versus INR levels below or above the thresholds of the therapeutic range

5. Timing of the antifibrinolytic intervention: before, during or after the oral or dental procedure

6. The number of extractions (single versus multiple extractions)

7. The location of extraction sites (maxilla or mandible)

We performed separate and combined analyses of different control groups (placebo and usual care), including one trial with two eligible usual care control groups. Further details are provided in Effects of interventions.

\section{Sensitivity analysis}

Given that we only included four trials, we were not able to undertake the planned sensitivity analyses.

1. Risk of bias: by excluding trials with an overall high risk of bias

2. Publication type: by excluding abstracts whose results cannot be confirmed in subsequent publications versus full texts papers 
3. Methodological aspects: by excluding non-blinded RCTs and by excluding non-standard designs, including versus excluding trials with missing data

\section{Summary of findings table}

The findings of the included trials are presented in a 'Summary of findings' table that contains the primary outcome measures. The absolute risks and the RDs $(95 \% \mathrm{Cl})$ are presented. This table also includes quality assessments for each primary outcome measure according to the GRADE approach (high, moderate, low or very low) (Schünemann 2011a; Schünemann 2011b). The numbers of participants and trials addressing these outcomes are summarized in the 'Characteristics of included studies' tables. The search process is summarized in the study flow diagram (Figure 1). We present the risk of bias assessments in the risk of bias tables (Characteristics of included studies) and summarize them in figure 2 (Figure 2). 
Figure 1. Study flow diagram.

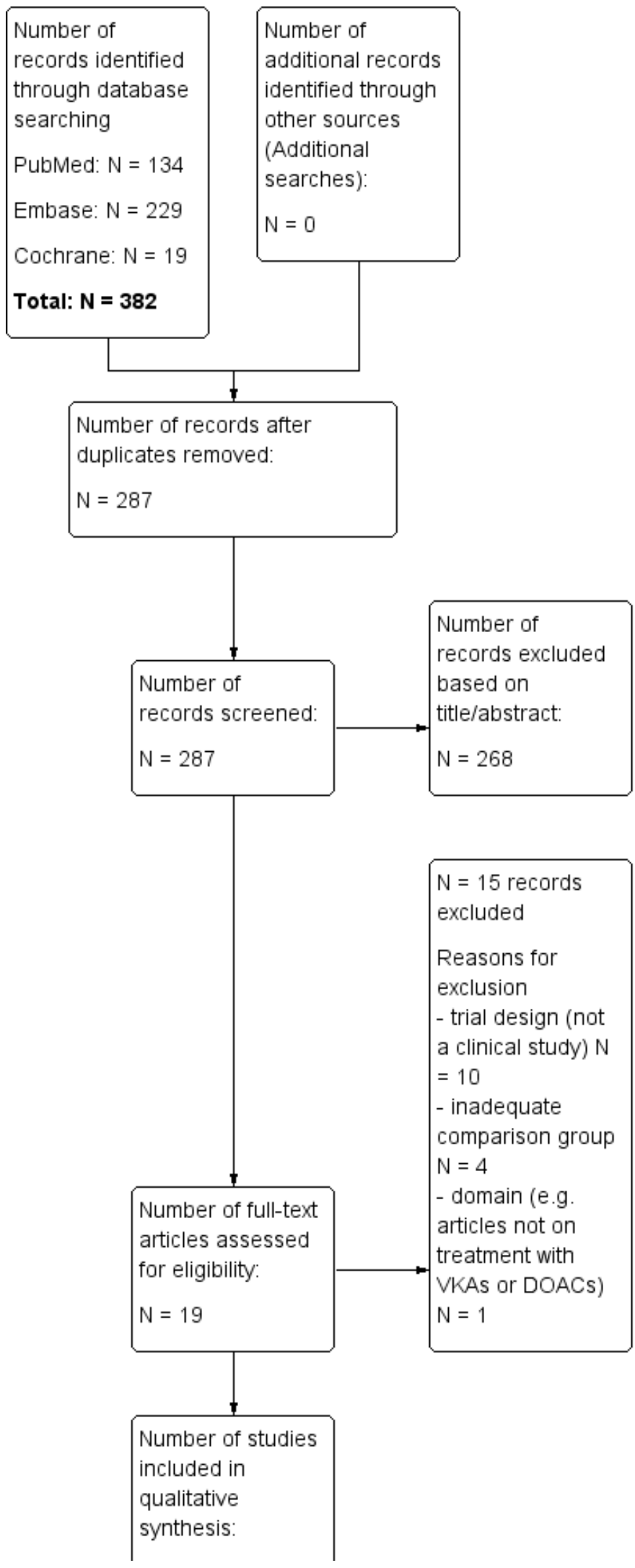


Figure 1. (Continued)

$\begin{aligned} & \text { synthesis: } \\ & N=4\end{aligned}$
$\begin{aligned} & \text { Number of studies } \\ & \text { included in } \\ & \text { quantitative } \\ & \text { synthesis } \\ & \text { (meta-analysis): } \\ & N=4\end{aligned}$


Figure 2. Risk of bias summary: review authors' judgements about each risk of bias item for each included study.

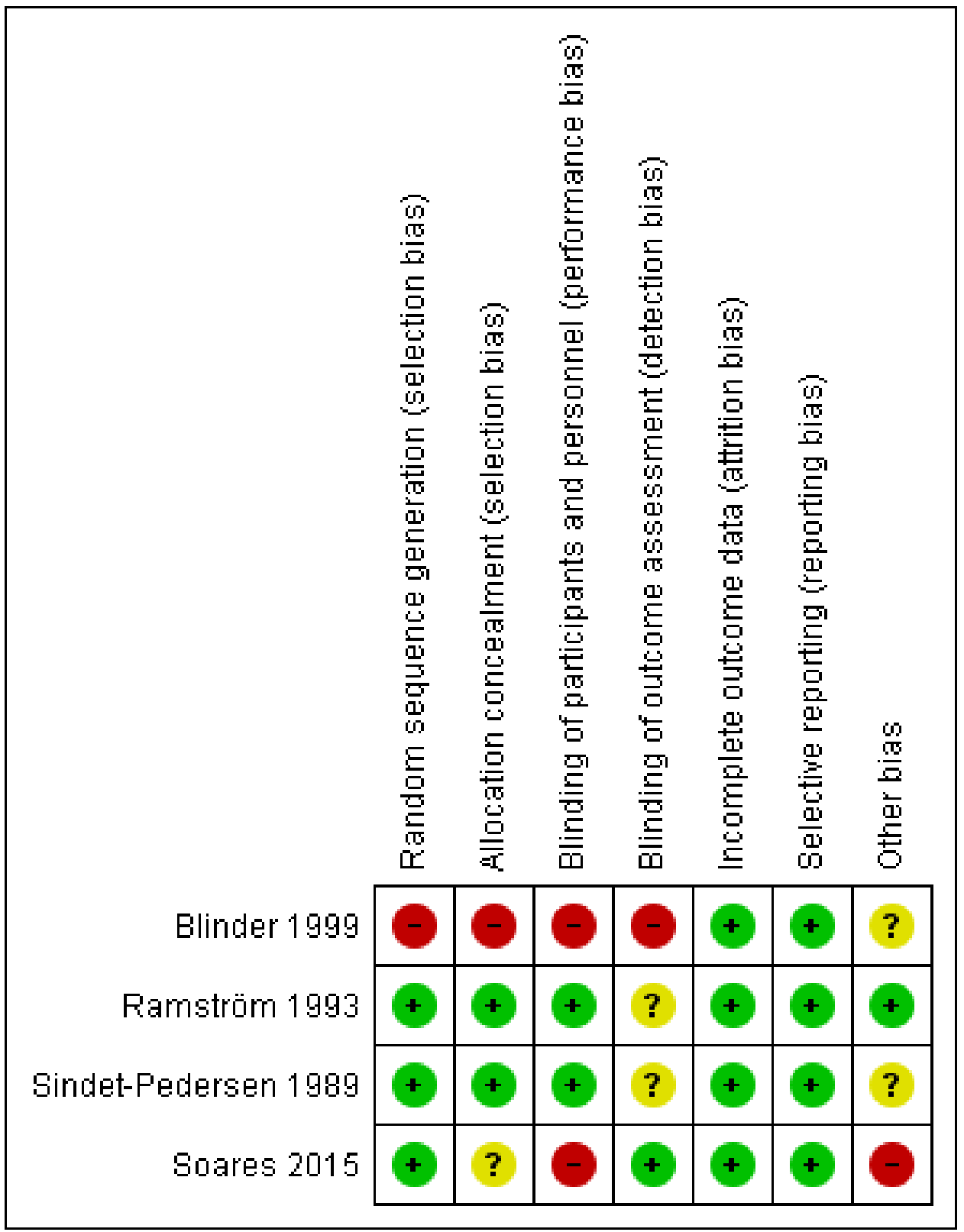

\section{RESULTS}

\section{Description of studies}

See: Characteristics of included studies and Characteristics of excluded studies.

\section{Results of the search}

The initial search yielded 382 articles as presented in the study flow diagram (Figure 1) (Liberati 2009). After removal of duplicates, 287 articles were screened on title and abstract. Full texts of the 19 articles that appeared to be potentially relevant were obtained. Four trials on people treated with VKAs were eligible for inclusion. No trials on people treated with DOACs were considered eligible for this review. Also, no eligible trials on EACA or systemically administered TXA were identified.
An ongoing trial was identified following correspondence with a peer reviewer (EXTRACT-NOAC 2018).

\section{Included studies}

The characteristics of the included trials are summarized in the Characteristics of included studies table.

\section{Trial design}

A total of four trials were included in the review; three RCTs (Ramström 1993; Sindet-Pedersen 1989; Soares 2015) and one quasi-RCT (Blinder 1999).

Antifibrinolytic therapy for preventing oral bleeding in people on anticoagulants undergoing minor oral surgery or dental extractions 


\section{Country}

Two of the included trials were conducted in Denmark and Sweden (Ramström 1993; Sindet-Pedersen 1989). The remaining trials were conducted in Israel (Blinder 1999) and Brazil (Soares 2015).

\section{Participants}

A total of 316 participants were discussed within the included articles, of which 253 participants were included in the analysis of this review. Participants in intervention groups receiving haemostatic agents other than antifibrinolytic therapy were excluded $(n=63)$.

The Sindet-Pedersen trial evaluated 39 participants on continuous treatment with VKAs at a therapeutic INR level (Sindet-Pedersen 1989). INR levels ranged from 2.5 to 4.8. The age of the included participants ranged from 19 to 77 years. A total of 118 procedures were performed: 98 dental extractions were performed in 33 participants, 14 retained teeth were removed in eight participants, five periapical surgical procedures were performed in three participants and one other procedure was performed in one participant. Participants could undergo multiple procedures, but it is unclear whether individuals underwent multiple randomisations. A mean of 2.8 and 3.3 teeth were extracted per participant in the placebo and TXA group respectively.

The Ramström trial evaluated 93 participants on continuous oral anticoagulant treatment with VKAs (phenprocoumon, warfarin or dicoumarol) at a therapeutic INR level (Ramström 1993). A total of 89 participants were included in the main efficacy analysis. INR levels ranged from 2.1 to 4.0. The participants were aged 53 to 87 years. Participants were referred for tooth extraction (single or multiple), surgical removal of retained tooth (single or multiple), or endodontic surgery. In the TXA group a mean number of 1.5 teeth per participant were extracted and a mean of 1.6 teeth per participant were surgically treated. In the placebo group a mean of 1.5 teeth per participant were extracted and a mean of 1.5 teeth per participant were surgically treated. Four participants were excluded from the main efficacy analysis, two because of incorrect inclusion (one on an anti-inflammatory agent and one subjected to an inappropriate type of surgery), and two because of incorrect multi-inclusion (the first treatment period was not finished before the participant was included in a second treatment period). Seven participants participated in the trial two or three times. The Ramström trial was conducted as a sequel to the SindetPedersen trial. There was no overlap between the participants in these trials (Ramström 1993; Sindet-Pedersen 1989).

The Soares trial included 41 individuals on continuous oral anticoagulant treatment with warfarin at a therapeutic INR level, who required the extraction of at least two teeth (Soares 2015). A total of 93 surgical procedures were randomised. A total of 38 instead of 41 participants were part of the analysis due to loss of follow-up. We have included the primary intervention group ( $\mathrm{N}$ $=12$ participants, $\mathrm{N}=28$ surgical procedures) and the dry gauze compression control group ( $\mathrm{N}=13$ participants, $\mathrm{N}=28$ surgical procedures). The haemostatic treatment in the second control group was not considered as standard care and this group was removed from further analysis in this review. The mean (standard deviation (SD)) INR level in the TXA group was $2.52(0.16)$, in the fibrin sponge group $2.51(0.16)$ and in the dry gauze group 2.51 (0.13). The age of the included participants ranged from 44 to 56 years. Due to loss of follow-up, 38 participants and a total of
84 dental extractions were analysed. Participants could receive different treatments. Reasons for extraction were dental caries and periodontal disease.

The Blinder trial evaluated 150 participants on continuous oral anticoagulant treatment with coumarin at a therapeutic INR level (Blinder 1999). INR levels ranged from 1.5 to 4.0. Participants ranged from 35 to 90 years of age and underwent a total of 359 dental extractions. Reasons for extraction were deep caries and periodontitis.

It is important to note that up to three trials include, or potentially include, participants who were randomised more than once.

\section{Interventions}

All four trials discussed the use of locally-applied TXA in people on continuous VKA treatment.

In two trials, the treatment regimen included irrigation with $10 \mathrm{~mL}$ 4.8\% TXA solution intra-operatively before suturing, and rinsing with $10 \mathrm{~mL}$ 4.8\% TXA mouthwash for two minutes four times daily for seven days postoperatively (Ramström 1993; Sindet-Pedersen 1989). The TXA solution was replaced by placebo solution in the control groups of these two trials (Ramström 1993; SindetPedersen 1989).

In the Soares trial, in the primary intervention group a gauze pad soaked in $4.8 \%$ TXA was applied to the surgical alveolus for eight minutes under biting pressure (Soares 2015). In the control group the dry gauze compression was performed under biting pressure on the surgical alveolus for eight minutes without the use of local haemostatic agents. In the second control group, another local haemostatic agent was used (not eligible for inclusion in this review); fibrin sponge was packed into the surgical alveolus and dry gauze compression was performed under biting pressure.

In the Blinder trial, participants in the intervention group received resorbable gelatin sponge and sutures intra-operatively, and TXA mouthwash $500 \mathrm{mg}$ for rinsing two minutes four times daily for a period of four days postoperatively, starting 24 hours after the procedure (Blinder 1999). The first control group received resorbable gelatin sponge and sutures only. A third group received resorbable gelatin sponge, sutures and fibrin glue. Also in this trial, the use of fibrin glue was not considered as standard care and this treatment group was therefore excluded from the analysis in this review.

\section{Outcome measures}

All trials reported the number of (participants with) postoperative bleedings as part of the outcomes (Blinder 1999; Ramström 1993; Sindet-Pedersen 1989; Soares 2015). Two trials reported the number and type of adverse effects (Sindet-Pedersen 1989; Ramström 1993). These same two trials also reported any postoperative complication except bleeding, such as wound infection. The number of immediate (less than 24 hours) and delayed ( 24 hours to 10 days) postoperative bleeding episodes requiring intervention was only reported by the Ramström trial (Ramström 1993).

Two trials discussed the possible correlation between the appearance of postoperative bleeding and the INR values as well as the number of bleeds in participants receiving multiple

Antifibrinolytic therapy for preventing oral bleeding in people on anticoagulants undergoing minor oral surgery or dental extractions 
extractions compared to those undergoing a single tooth extraction (Blinder 1999; Soares 2015). Two trials reported on the need for additional local haemostatic measures (e.g. vitamin $\mathrm{K}$ and freshfrozen plasma) (Ramström 1993; Sindet-Pedersen 1989).

\section{Excluded studies}

The characteristics of the 15 excluded trials are summarized in the Characteristics of excluded studies table. The reasons for exclusion were trial design (not a clinical trial or not (quasi)-randomised) (Bublitz 2000; Chow 2003; Gaspar 1997; Goss 2002; Hoppe 1969; Keiani 2003; Kwapis 1963; McIntyre 1966; Somma 2010; Timocin 1996), inadequate comparison group (Borea 1993; Bucciarelli 1997; Carter 2003; Souto 1996) and domain (e.g. articles not on treatment with VKAs or DOACs) (Sammartino 2012).

\section{Ongoing studies}

One ongoing trial was identified (EXTRACT-NOAC 2018); further details are provided in the tables (Characteristics of ongoing studies).

\section{Risk of bias in included studies}

Detailed quality assessments are presented in the 'Risk of bias' tables presented with each trial in the Characteristics of included studies table. In addition, the risk of bias of each trial is summarized in Figure 2.

Of the four included trials, we considered three to have an overall low risk of bias (Ramström 1993; Sindet-Pedersen 1989; Soares 2015) and one to have a high risk of bias (Blinder 1999).

\section{Allocation}

\section{Sequence generation}

The Soares trial reported the use of a computer-generated code in the randomisation process and was judged to have a low risk of bias for this domain (Soares 2015). A further two trials stated that they used randomly numbered medication packages to assign participants, and although they did not report the exact method of sequence generation, we still regard the risk of selection bias to be low (Ramström 1993; Sindet-Pedersen 1989).

The risk of selection bias due to sequence generation was considered to be high in the Blinder trial (Blinder 1999). In the Blinder trial, assignment was based on the day on which the procedure was performed (Blinder 1999).

\section{Allocation concealment}

The risk of selection bias due to inadequate allocation concealment was considered to be: low in the Ramström trial and the SindetPedersen trials (Ramström 1993; Sindet-Pedersen 1989); high in the Blinder trial (Blinder 1999); and unclear in the Soares trial (Soares 2015).

In the Ramström and Sindet-Pedersen trials, participants were randomised to consecutively numbered medication packages (Ramström 1993; Sindet-Pedersen 1989). Both trials stated that a pre-determined treatment regimen was used for participants presenting with postoperative bleeding. In the Ramström trial, it was also reported that sealed envelopes with information about the randomisation code for each participant were used. These envelopes could be opened in case of emergency.
The risk of bias was considered to be high in the Blinder trial (Blinder 1999), the allocation was not concealed and it was based on the day the procedure was performed.

The Soares trial reported the use of a computer-generated code for random allocation; however, the method of allocation concealment was not described (Soares 2015).

\section{Blinding}

The risk of performance bias and detection bias was considered to be low in the Ramström and Sindet-Pedersen trials (Ramström 1993; Sindet-Pedersen 1989). Both trials were carried out as double-blind trials with both groups following the same treatment schedule with either tranexamic acid solution or an apparently identical placebo solution.

The risk of performance bias (blinding of participants and personnel) was considered to be high in the Soares and Blinder trials, as the type of intervention and control treatment regimens did not allow for blinding personnel and participants (Blinder 1999; Soares 2015).

The risk of detection bias (blinding of outcome assessment) was considered to be high in the Blinder trial, as treatment allocation was based on the day of the procedure in the first trial (Blinder 1999). The risk of detection bias was considered to be low in the Soares trial; the Soares trial stated that the investigator who was responsible for the outcome assessment was blinded to the haemostatic protocol allocation throughout the trial period (Soares 2015). The risk of detection bias was considered to be unclear in the Ramström trial and the Sindet-Pedersen trials as the blinding of outcome assessment was not discussed in either of the articles (Ramström 1993; Sindet-Pedersen 1989).

\section{Incomplete outcome data}

The risk of attrition bias was considered to be low in all of the included trials (Blinder 1999; Ramström 1993; SindetPedersen 1989; Soares 2015). In the Blinder trial and SindetPedersen trial, all included participants were analysed. In the Ramström trial there was no loss to follow-up and the reasons for excluding four participants from the main efficacy analysis after randomisation were discussed in the article. In the Ramström trial, two participants were excluded after randomisation because of incorrect inclusion and two because of incorrect multi-inclusion (the first treatment period was not finished before the patient was included in a second). In the Soares trial, nine surgical procedures from three participants were lost to follow-up, as these participants did not return for evaluation. These participants were not included in the analysis. As the percentage of participants that was lost to follow-up was below $10 \%$, the risk of attrition bias by loss to followup was still considered to be low in this trial (Soares 2015).

\section{Selective reporting}

The risk of reporting bias was considered to be low in all of the included trials. All pre-specified outcome measures were reported.

\section{Other potential sources of bias}

The poor reporting of data in the Blinder trial presents an extra source of bias (Higgins 2011c); the quality of reporting results within this trial was considered to be doubtful as group numbers and corresponding treatments were exchanged between the tables 
and parts of the text (Blinder 1999). However, each group number mentioned in the text was consistently followed by describing the corresponding treatment group. Because the described results did match the results tables, we believed data extraction was sufficiently reliable to include this trial in the current review.

Furthermore, in both the Soares and the Ramström trials, participants were randomised more than once (Ramström 1993; Soares 2015). In the Blinder and Sindet-Pedersen trials, it was unclear whether or not participants could undergo multiple randomisations (Sindet-Pedersen 1989; Blinder 1999). See the Characteristics of included studies section for more information on the individual assessments.

\section{Effects of interventions}

\section{See: Summary of findings for the main comparison}

Detailed assessments (gradings) of the primary outcomes of this review, as reported in the included trials, are described in the 'Summary of findings table', for the definitions of these gradings, please refer to the summary of findings tables (Summary of findings for the main comparison).

The primary aim of the review was to assess the efficacy of antifibrinolytic agents (TXA or EACA) to prevent bleeding complications in people on unchanged, continuous oral anticoagulant treatment undergoing oral or dental procedures.

A potential unit of analysis issue is the fact that two of the included trials included participants that were randomised more than once (Ramström 1993; Soares 2015). In the Ramström trial, seven individuals participated in the study two or three times. In the Soares trial, extraction sites were considered as sampling units and these were allocated to different treatment groups (Soares 2015). In two other included trials it was unclear whether participants could undergo multiple randomisations (Blinder 1999; Sindet-Pedersen 1989).

During the selection process, one trial was discussed between the authors due to initial disagreement about whether to include the trial or not (Blinder 1999). The quality of reporting results within this trial was considered to be doubtful as group numbers and corresponding treatments were exchanged between the tables and parts of the text. However, the trial was included because of eligibility in terms of design, participants and outcomes. Also, each group number mentioned in the text was consistently followed by describing the corresponding treatment group and because the described results did match the results tables, data extraction could reliably be performed and the trial was eventually included in this review.

There was substantial heterogeneity in the results. We believed this was due to several reasons. Firstly, there was clinical diversity within the included trials, with much heterogeneity in the included comparison groups (both placebo and different standard care groups), as well as heterogeneity in TXA regimens (e.g. different frequency and duration of administration). Furthermore, there was methodological diversity, with one out of the four included trials being a quasi-randomised trial. Finally, a relatively small number of participants were included in the trials.

\section{Antifibrinolytic therapy versus placebo or standard care}

In the trial reports, a total of 316 participants were discussed, of which 253 were eligible for this review. Participants in those intervention groups receiving haemostatic agents other than antifibrinolytic therapy were excluded.

\section{Primary outcomes}

\section{Number of participants with postoperative bleedings requiring intervention}

All included trials evaluated the efficacy of antifibrinolytic agents for preventing bleeding complications in individuals on continuous treatment with an oral anticoagulant. The Sindet-Pedersen trial and Ramström trial showed a statistically significant and beneficial effect of TXA compared with placebo with a pooled RD of -0.25 ( $95 \% \mathrm{Cl}-0.36$ to -0.14 ) (63 versus 65 participants) (moderate-quality evidence) (Analysis 1.1; Figure 3) (Sindet-Pedersen 1989; Ramström 1993). The NNT for TXA when compared to placebo is four. There was no difference between the TXA and the standard care group with a pooled $\mathrm{RD}$ of $0.02(95 \% \mathrm{Cl}-0.07$ to 0.11$)$ (62 versus 63 participants) (moderate-quality evidence) (Analysis 1.1) (Blinder 1999; Soares 2015). 
Figure 3. Forest plot of comparison: 1 Antifibrinolytic therapy versus placebo or standard care, outcome: 1.1 Number of people with postoperative bleedings.

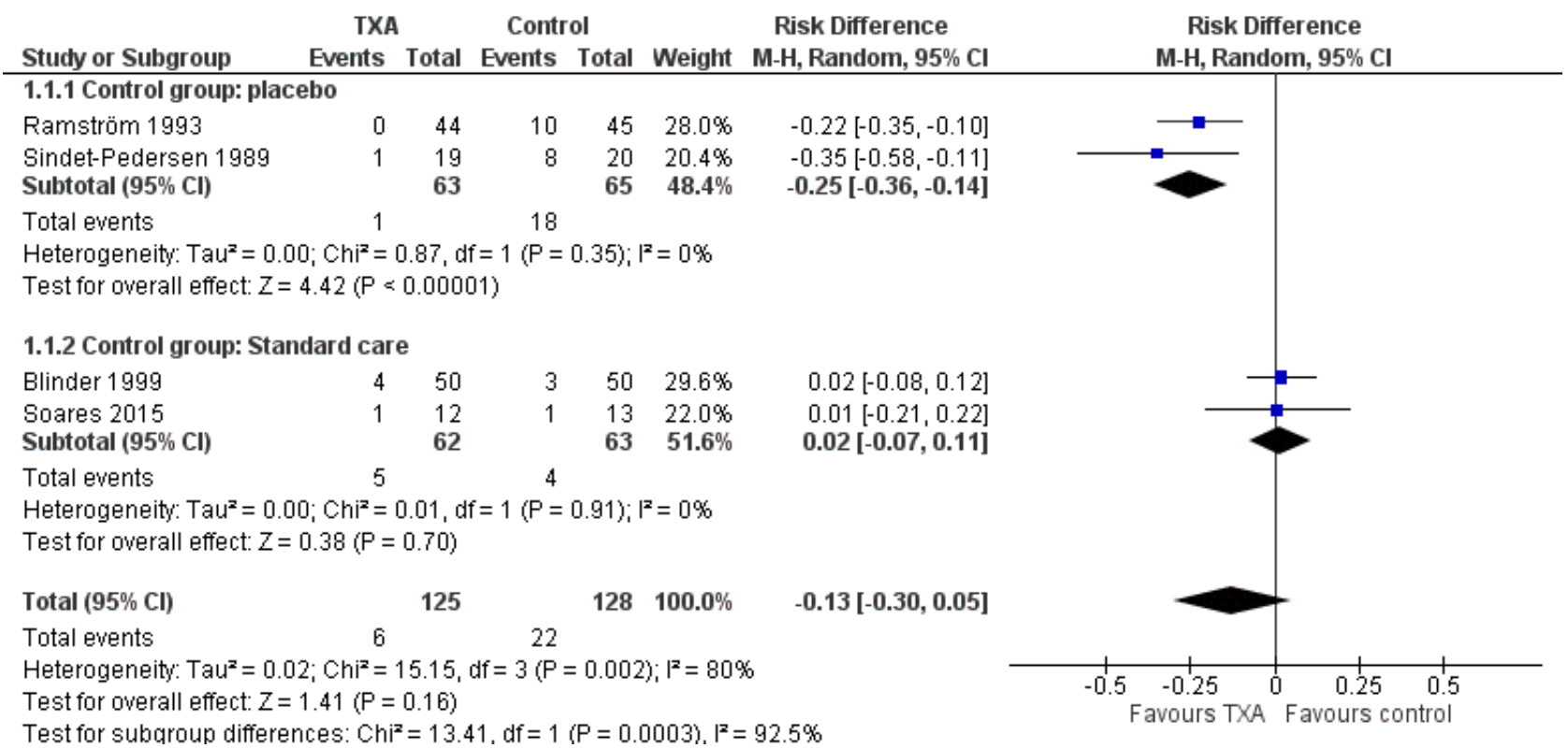

\section{Side effects or other adverse events}

Two of the included trials reported side effects as an outcome (Ramström 1993; Sindet-Pedersen 1989). In both trials there were no side effects requiring withdrawal from the trial treatment, with a combined RD of 0.00 (95\% Cl -0.04 to 0.04$)$ (128 participants) (moderate-quality evidence) (Analysis 1.2).

In the Ramström trial, while no participant stopped using the mouthwash because of adverse effects, it was reported that 6 of the 46 participants in the TXA group reported adverse effects such as a bad or sour taste $(n=3)$, nausea $(n=1)$, tedious treatment $(n=1)$ or a slight burning feeling $(n=1)$. A total of 4 of the 47 participants in the placebo group reported adverse effects such as nausea ( $n=$ 2 ) and bad taste $(n=2)$ (Ramström 1993). The Sindet-Pedersen trial reported that there were no systemic side effects (39 participants) (Sindet-Pedersen 1989).

\section{Secondary outcomes}

The secondary outcomes measures 'number of people with minor postoperative bleeding', 'number of people with complications other than bleeding', 'the number of people with bleeding requiring transfusion' and 'the number of immediate and delayed postoperative bleedings' were reported in one or more of the included trials (Analysis 1.3; Analysis 1.4; Analysis 1.5; Analysis 1.6).

The remaining secondary outcomes (e.g. change in haemoglobin level, duration of bleeding and amount of postoperative blood loss) were not reported in the included trials. Therefore, no MDs with corresponding 95\% Cls could be calculated.

The Blinder trial reported an association between bleeding and the presence of severe periodontitis (Blinder 1999). Participants who underwent multiple extractions did not bleed from all extraction sites, bleeding rather occurred in the sites associated with severe periodontitis.

\section{Number of minor postoperative bleeding episodes}

The number of people with minor postoperative bleeding was reported in two of the included trials (Ramström 1993; Sindet-Pedersen 1989). The Sindet-Pedersen trial showed minor postoperative bleeding in 4 out of 20 (20\%) of the participants of the placebo group and in none of the 19 participants in the TXA group (Sindet-Pedersen 1989). In the Ramström trial, minor bleeding occurred in none of the 45 participants in the placebo group and in 2 out of 44 (4.5\%) of the participants in the TXA group (Analysis 1.3) (Ramström 1993). All minor bleeding episodes were haematoma which abated spontaneously. The pooled RD between the TXA versus the placebo groups was $-0.06(95 \% \mathrm{Cl}-0.33$ to 0.20$)$ (128 participants) (Analysis 1.3).

\section{Number of immediate (less than 24 hours) and delayed ( 24 hours to} 10 days) postoperative bleeding episodes requiring intervention

In the Ramström trial all bleedings occurred 1, 3 or 5 days after oral surgery (Analysis 1.4) (Ramström 1993). In this trial, the RD was statistically significant, -0.22 ( $95 \% \mathrm{Cl}-0.35$ to -0.10$)$ (89 participants) (Analysis 1.4). The Blinder trial did not report the exact number of immediate and delayed postoperative bleeding episodes; however, it did report the mean number of days after which postoperative bleeding occurred in the different treatment groups (Blinder 1999). On average, bleeding occurred 0.9 days postoperatively in the collagen group, 4.0 days postoperatively in the TXA group and 3.9 days in the mucosal flap group. The other included trials did not report this outcome (Sindet-Pedersen 1989; Soares 2015).

\section{Any postoperative complication except bleeding}

This outcome was reported in the Ramström and Sindet-Pedersen trials (Ramström 1993; Sindet-Pedersen 1989). In the Ramström trial (89 particpants) one perforation of the maxillary sinus was observed in the placebo group ( $n=45)$ (Ramström 1993). No participant had a fever or signs of infection. The Sindet-Pedersen trial (39 participants) reported that no complications other than bleeding were observed (Sindet-Pedersen 1989). The pooled RD

Antifibrinolytic therapy for preventing oral bleeding in people on anticoagulants undergoing minor oral surgery or dental extractions 
was statistically not significant with $-0.02(95 \% \mathrm{Cl}-0.07$ to 0.03$)(128$ participants) (Analysis 1.5).

\section{Change in haemoglobin level from baseline}

This outcome was not reported in any of the included trials.

\section{Major bleeding, requiring transfusion of packed red blood cells}

With regards to the placebo-controlled trials, the Ramström trial (89 participants) reported that there was no major bleeding in any of the participants of the control and TXA group (Ramström 1993). The Sindet-Pedersen trial reported one major bleeding episode requiring fresh frozen plasma in 1 out of 20 participants of the control group (5\%) and in none out of 19 of the participants in the TXA group (Sindet-Pedersen 1989). For those trials comparing TXA to standard care, the Blinder trial reported that all bleeds were stopped by local haemostatic measures (100 participants) (Blinder 1999). In relation to Soares trial, it was reported that none of the participants required any transfusion (25 participants). The pooled results for these four trials was RD -0.00 ( $95 \% \mathrm{Cl}-0.03$ to 0.03$)$ (253 participants) (Analysis 1.6).

\section{Bleeding duration}

This outcome was not reported in any of the included trials.

\section{Amount of postoperative blood loss $(\mathrm{mL})$}

This outcome was not reported in any of the included trials.

\section{Number of thromboembolic complications}

This outcome was not reported in any of the included trials.

\section{DISCUSSION}

\section{Summary of main results}

In this systematic review on antifibrinolytic therapy for preventing oral bleeding in people on continuous oral anticoagulant treatment undergoing oral or dental procedures, we included four trials (three RCTs, one quasi-RCT) (253 participants). All of the included trials studied individuals on continuous treatment with VKAs and used TXA as antifibrinolytic treatment. No eligible trials on treatment with DOACs regarding this subject were identified.

The two trials comparing the use of TXA with the use of placebo (128 participants) showed a statistically significant and beneficial effect of TXA. These were also the trials with the lowest risk of bias (Ramström 1993; Sindet-Pedersen 1989). Interestingly, the two trials (125 participants) comparing TXA with standard care showed that TXA was not more efficient than other local measures. However, this difference was not statistically significant and no clear conclusion can be drawn based on the results of these two trials. The Blinder trial (TXA versus standard care) also showed an association between bleeding and the presence of severe periodontitis (100 participants) (Blinder 1999). Severe periodontitis was the cause for extraction in 109 teeth in the TXA group and in 87 teeth in the control group. The relatively small sample sizes and heterogeneity with regard to the standard therapy and treatment regimens do not allow us to conclude definite efficacy of antifibrinolytic therapy in oral or dental procedures in individuals on continuous treatment with an oral anticoagulant.

In total 253 participants were included in the current meta-analysis; 125 participants on TXA and 128 participants on standard therapy or placebo. In the Ramström trial only the mean number of extracted teeth was reported. The primary endpoint (bleeding needing intervention) occurred in 6 out of 125 (4.8\%) participants treated with TXA versus 22 out of $128(17 \%)$ of the participants in the comparison groups. Almost all bleedings were manageable by local haemostatic means. In less then $1 \%$ (1 out of 253 ) of the included participants in this review local haemostasis was not sufficient.

Between the included trials there was much heterogeneity regarding the treatment type and treatment regimen of the control groups. Control treatments included placebo solutions, dry gauze compression, collagen fleece, mucosal flap placement and a combination of gelatin sponge and sutures. The definition of postoperative bleeding was reasonably comparable between the included trials; three trials defined bleeding as postoperative bleeding that could not be controlled by compression with gauze for 20 minutes (Ramström 1993; Sindet-Pedersen 1989; Soares 2015) and one trial as bleeding requiring intervention (Blinder 1999).

\section{Overall completeness and applicability of evidence}

Due to the set up of comprehensive literature searches, it is likely that all relevant trials for this review were identified.

The results apply to people on continuous treatment with VKAs within the therapeutic range undergoing oral or dental procedures. The applied therapeutic range in the included trials ranged from 1.5 to 4.0, except for the Sindet-Pedersen trial, where INR levels ranged from 2.5 to 4.8 . Therefore, there is only marginal heterogeneity with respect to the INR levels of the included participants in this review. Since we identified no eligible trials in individuals on continuous treatment with DOACs undergoing oral or dental procedures, a possible beneficial effect of TXA for these individuals remains to be established.

A potential bias favouring TXA in the placebo-controlled trials could be a potential harmful effect of the placebo intervention that consisted of irrigation and mouthwash with a non-haemostatic placebo solution (Ramström 1993; Sindet-Pedersen 1989). There is a theoretic possibility that this placebo treatment hampered wound healing.

\section{Quality of the evidence}

Only four trials in individuals on continuous oral anticoagulant treatment undergoing oral or dental procedures met the inclusion criteria for this systematic review. In relation to the two primary outcomes of number of postoperative bleeds and side effects of therapy, using the GRADE assessment, we judged the quality of the evidence from this review to be of moderate quality (Summary of findings for the main comparison).

In the two trials comparing TXA with placebo the risk of bias was considered to be low (Ramström 1993; Sindet-Pedersen 1989), in the remaining trials it was considered to be moderate (Blinder 1999; Soares 2015). This was mainly due to the lack of blinding and inadequate allocation concealment in one of these trials (Blinder 1999). There were many differences between the trials with regards to treatment regimens in the different control groups. It is important to note that from the four trials included in this review, the risk of bias was increased given that in two trials the participants were definitely randomised more than once (Ramström 1993; Soares 2015) and in two further trials this

Antifibrinolytic therapy for preventing oral bleeding in people on anticoagulants undergoing minor oral surgery or dental extractions 19 (Review) 
was possibly the case (Ramström 1993; Sindet-Pedersen 1989), increasing the risk of bias.

Due to the small amount of available trials in the literature, small sample sizes and the heterogeneity in treatment of the control groups, we rated the overall quality of the evidence as moderate. The evidence in this review does not allow a robust conclusion regarding the efficacy of antifibrinolytic agents to prevent bleeding complications after oral or dental procedures in people on VKAs and no conclusion on those using DOACs due to the absence of eligible clinical trials.

\section{Potential biases in the review process}

Since two authors independently screened the articles and collected the data, potential biases in the review process were minimized. One trial was discussed between the authors due to initial disagreement and finally included and rated as a high-risk-ofbias trial (Blinder 1999). Furthermore, exclusion of this trial would not significantly influence the overall results of this review. There were no differences between the authors regarding data extraction and all relevant data could be obtained. It is therefore unlikely that these items could have introduced bias.

\section{Agreements and disagreements with other studies or reviews}

Two of the trials from this Cochrane Review (Ramström 1993; Sindet-Pedersen 1989) were also included in another review that examined the use of local haemostatic measures in anticoagulated patients undergoing oral surgery (Costa 2013). The review, which also included non-randomised trials, showed that TXA was more effective in controlling bleeding when compared to oxidized cellulose and other local measures. The findings from our review are in correlation with this previously published article.

A recently published Dutch trial showed that, in low-risk procedures (e.g. extraction of one to three teeth), VKA continuation with TXA mouthwash was associated with a lower risk of postoperative bleeding when compared to continuation without TXA or interruption and bridging with low molecular weight heparin (LMWH). VKA continuation with TXA mouthwash carried a similar bleeding risk as interruption without bridging (Biedermann 2017). The strongest predictors of postoperative bleeding were bridging with $\mathrm{LWMH}$, antiplatelet therapy, and a supra-therapeutic or unknown INR before the procedure. In high-risk procedures (e.g. extraction of more than three teeth), VKA continuation was associated with an increased bleeding risk postoperatively when compared to interruption without bridging (Biedermann 2017).

We did not systematically review evidence from non-randomised studies. These studies generally comprise prospective and retrospective cohort studies. In general, these studies were supportive of the use of TXA and EACA with few side effects (Bublitz 2000; Keiani 2003; Somma 2010; Souto 1996). One representative study considered 40 people on continuous treatment with a VKA (acenocoumarol) (Keiani 2003). Participants were subjected to treatment with TXA during and after the oral or dental procedure. No postoperative bleedings occurred.

Gradually VKAs are replaced by DOACs in those at a risk of thromboembolic events. No RCTs discussing antifibrinolytic therapy in people on DOAC treatment were identified through the search strategy. Cena reviewed the evidence of different treatment approaches in people on DOACs undergoing oral surgery, but no conclusion could be drawn, as no head-to-head comparative study has been undertaken. The reference list of this review did not yield any eligible trials that were not yet identified by our primary literature search (Cena 2016). However, this issue is probably less relevant in routine clinical practice, since discontinuation of DOACs can be executed for a very short period due to their short halflife compared to VKAs, diminishing the risks of both bleeding and thromboembolic complications as compared to VKAs in the majority of individuals.

A RCT on the use of TXA in people treated with DOACs undergoing dental extraction has been awarded funding in Belgium in July 2017 (EXTRACT-NOAC 2018). We anticipate that this trial will be eligible for inclusion in this review.

\section{AUTHORS' CONCLUSIONS}

\section{Implications for practice}

Based on the results of this Cochrne Review, there is some evidence for effectiveness and no evidence of potential harm regarding the use of locally applied tranexamic acid (TXA) in preventing oral bleeding in people using oral anticoagulants undergoing minor oral surgery or dental extractions. However, there is no clear superior effect of TXA compared to alternative haemostatic measures. The use of antifibrinolytic agents in people on direct oral anticoagulants (DOACs) undergoing oral or dental procedures is not evidencebased since we found no randomised controlled trials in this population. Pathophysiologic considerations, in combination with the presented data on individuals using vitamin $\mathrm{K}$ antagonists (VKAs), can give some rationale for its use in clinical practice.

\section{Implications for research}

The data to support the use of antifibrinolytic therapy for preventing bleeding during or after oral or dental procedures in people on oral anticoagulant treatment is of moderate quality. In order to be conclusive, further research is required on individuals continuing oral anticoagulant treatment within the therapeutic range undergoing oral or dental procedures with clearly defined participant characteristics, equal concomitant standard therapy in the intervention and control groups and a statistically sufficient sample size. Further research is needed to confirm the association between bleeding and the presence of severe periodontitis, as described in one of the included articles, and to find out whether TXA has a role to prevent bleeding in these cases. The effect of the systemic use of TXA versus locally applied TXA solution remains to be determined, as well as the effect of antifibrinolytic therapy on oral bleeding in individuals continuing DOACs during oral or dental procedures.

\section{ACKNOWLEDGEMENTS}

We thank Bianca Kramer, clinical librarian, the Dutch Cochrane Center and the Cochrane Cystic Fibrosis and Genetic Disorders Group for their help in starting up and conducting this systematic review.

This project was supported by the National Institute for Health Research, via Cochrane Infrastructure funding to the Cochrane Cystic Fibrosis and Genetic Disorders Group. The views and opinions expressed therein are those of the authors and do not 
necessarily reflect those of the Systematic Reviews Programme, NIHR, NHS or the Department of Health. 


\section{RE F E R E N C E S}

\section{References to studies included in this review}

Blinder 1999 \{published data only\}

Blinder D, Manor Y, Martinowitz U, Taicher S, Hashomer T. Dental extractions in patients maintained on continued oral anticoagulant: comparison of local hemostatic modalities. Oral Surgery, Oral Medicine, Oral Pathology, Oral Radiology, and Endodontics 1999;88(2):137-40. [PUBMED: 10468454]

\section{Ramström 1993 \{published data only\}}

Ramström G, Sindet-Pedersen S, Hall G, Blomback M, Alander U. Prevention of postsurgical bleeding in oral surgery using tranexamic acid without dose modification of oral anticoagulants. Journal of Oral and Maxillofacial Surgery 1993;51(11):1211-6. [PUBMED: 8229393]

\section{Sindet-Pedersen 1989 \{published data only\}}

Sindet-Pedersen S, Ramstrom G, Bernvil S, Blomback M. Hemostatic effect of tranexamic acid mouthwash in anticoagulant-treated patients undergoing oral surgery. New England Journal of Medicine 1989;320(13):840-3. [PUBMED: 2648144]

\section{Soares 2015 \{published data only\}}

Soares EC, Costa FW, Bezerra TP, Nogueira CB, de Barros Silva PG, Batista SH, et al. Postoperative hemostatic efficacy of gauze soaked in tranexamic acid, fibrin sponge, and dry gauze compression following dental extractions in anticoagulated patients with cardiovascular disease: a prospective, randomized study. Oral and Maxillofacial Surgery 2015;19(2):209-16. [PUBMED: 25528251]

\section{References to studies excluded from this review}

\section{Borea 1993 \{published data only\}}

Borea G, Montebugnoli L, Capuzzi P, Magelli C. Tranexamic acid as a mouthwash in anticoagulant-treated patients undergoing oral surgery. An alternative method to discontinuing anticoagulant therapy. Oral Surgery, Oral Medicine, and Oral Pathology 1993;75(1):29-31. [PUBMED: 8419869]

\section{Bublitz 2000 \{published data only\}}

Bublitz R, Sommer S, Weingart D, Bauerle K, Both A. Hemostatic wound management in marcumar patients. Collagen fleece vs. tranexamic acid [Hamostyptische Wundversorgung bei Marcumarpatienten. Kollagenvlies vs. Tranexamsaure.]. Mund-, Kiefer- und Gesichtschirurgie : MKG 2000;4(4):240-4. [PUBMED: 10994324]

\section{Bucciarelli 1997 \{published data only\}}

Bucciarelli P, Ginelli G, Misani M, Moia M. Fibrin glue plus tranexamic acid mouthwashing in patients on oral anticoagulants undergoing dental extractions: a randomised study. Thrombosis and Haemostasis 1997:1517.

\section{Carter 2003 \{published data only\}}

Carter G, Goss A, Lloyd J, Tocchetti R. Tranexamic acid mouthwash versus autologous fibrin glue in patients taking warfarin undergoing dental extractions: a randomized prospective clinical study. Journal of Oral and Maxillofacial Surgery 2003;61(12):1432-5. [PUBMED: 14663808]

Chow 2003 \{published data only\}

Chow KM, Szeto CC. Oral anticoagulant and dental procedures. Archives of Internal Medicine 2003; Vol. 163, issue 20:2532; author reply 2533. [PUBMED: 14609793]

\section{Gaspar 1997 \{published data only\}}

Gaspar R, Brenner B, Ardekian L, Peled M, Laufer D. Use of tranexamic acid mouthwash to prevent postoperative bleeding in oral surgery patients on oral anticoagulant medication. Quintessence International (Berlin, Germany: 1985) 1997;28(6):375-9. [PUBMED: 9477900]

Goss 2002 \{published data only\} Goss A.N. Carter G. Dental patients receiving warfarin therapy. Australian Prescriber 2002;25(5):105-106.

Hoppe 1969 \{published data only\}

Hoppe W. Marcumar therapy and dental surgery [Marcumarbehandlung und zahnarztlich-chirurgische Eingriffe.]. Zahnarztliche Welt, zahnarztliche Rundschau, ZWR, vereinigt mit Zahnarztliche Reform 1969;78(21):977-9. [PUBMED: 5260268]

\section{Keiani 2003 \{published data only\}}

Keiani Motlagh K, Loeb I, Legrand W, Daelemans P, Van Reck J. Prevention of postoperative bleeding in patients taking oral anticoagulants. Effects of tranexamic acid [Prevention des saignements postoperatoires chez des patients sous anticoagulants oraux. Effets de l'acide tranexamique]. Revue de Stomatologie et de Chirurgie Maxillo-faciale 2003;104(2):77-9. [PUBMED: 12750624]

Kwapis 1963 \{published data only\} KWAPIS BW. Anticoagulant therapy and dental practice. Journal of the American Dental Association (1939) 1963;66:172-5. [PUBMED: 13927749]

\section{McIntyre 1966 \{published data only\}}

McIntyre $\mathrm{H}$. Management, during dental surgery, of patients on anticoagulants. Lancet (London, England) 1966;2(7454):99-100. [PUBMED: 4161034]

\section{Sammartino 2012 \{published data only\}}

Sammartino G, Marenzi G, Miro A, Ungaro F, Nappi A, Sammartino JC, et al. Local delivery of the hemostatic agent tranexamic acid in chronically anticoagulated patients. Journal of Craniofacial Surgery 2012;23(6):e648-52. [PUBMED: 23172514]

\section{Somma 2010 \{published data only\}}

Somma F, Grande NM, Plotino G, Cameli G, Pameijer CH. Conservative approach to dental extractions in patients on anticoagulant therapy: a clinical study. General Dentistry 2010;58(1):e30-5. [PUBMED: 20129880]

Antifibrinolytic therapy for preventing oral bleeding in people on anticoagulants undergoing minor oral surgery or dental extractions 


\section{Souto 1996 \{published data only\}}

Souto JC, Oliver A, Zuazu-Jausoro I, Vives A, Fontcuberta J. Oral surgery in anticoagulated patients without reducing the dose of oral anticoagulant: a prospective randomized study. Journal of Oral and Maxillofacial Surgery 1996;54(1):27-32; discussion 323. [PUBMED: 8530996]

\section{Timocin 1996 \{published data only\}}

Timocin N. Kocak H. Gurkan B. Oner B. Effect of tranexamic acid (transamine) mouthwash after dental extraction in patients who received anticoagulant agents. Istanbul Tip Fakultesi Mecmuasi 1996;59:2:37-40

\section{References to ongoing studies}

\section{EXTRACT-NOAC 2018 \{published data only\}}

OMFS-IMPATH Research Group. EXTRACT-NOAC. Use of new oral anticoagulants in oral surgery. http://omfsimpath.be/research1/ extract-noac.html (accessed 27 April 2018).

\section{Additional references}

\section{Adcock 2015}

Adcock DM, Gosselin R. Direct Oral Anticoagulants (DOACs) in the Laboratory: 2015 Review. Thrombosis Research 2015;136(1):7-12. [PUBMED: 25981138]

\section{Ansell 2004}

Ansell J, Hirsh J, Poller L, Bussey H, Jacobson A, Hylek E. The pharmacology and management of the vitamin $\mathrm{K}$ antagonists: the Seventh ACCP Conference on Antithrombotic and Thrombolytic Therapy. Chest 2004;126(3 Suppl):204S-33S [PUBMED: 15383473]

\section{Ascani 1999}

Ascani A, lorio A, Agnelli G. Withdrawal of warfarin after deep vein thrombosis: effects of a low fixed dose on rebound thrombin generation. Blood Coagulation \& Fibrinolysis 1999;10(5):291-5. [PUBMED: 10456621]

\section{Biedermann 2017}

Biedermann JS, Rademacher WMH, Hazendonk HCAM, van Diermen DE, Leebeek FWG, Rozema FR, et al. Predictors of oral cavity bleeding and clinical outcome after dental procedures in patients on vitamin $\mathrm{K}$ antagonists. A cohort study. Thrombosis and Haemostasis 2017;117(7):1432-9. [PUBMED: 28405671]

\section{Cena 2016}

Cena D, Lidija P, Milka Z, Mirjana P, Katerina Z. Traditional versus new oral anticoagulants in clinical practice of oral surgery. Research Journal of Pharmaceutical, Biological and Chemical Sciences 2016;7(5):170-7.

\section{Costa 2013}

Costa FW, Rodrigues RR, Sousa LH, Carvalho FS, Chaves FN, Fernandes $\mathrm{CP}$, et al. Local hemostatic measures in anticoagulated patients undergoing oral surgery: a systematized literature review. Acta Cirurgica Brasileira 2013;28(1):78-83. [PUBMED: 23338118]

\section{Cundiff 2008}

Cundiff DK. Clinical evidence for rebound hypercoagulability after discontinuing oral anticoagulants for venous thromboembolism. Medscape Journal of Medicine 2008;10(11):258. [PUBMED: 19099008]

\section{Deeks 2011}

Deeks JJ, Higgins JPT, Altman DG on behalf of the Cochrane Statistical Methods Group. Chapter 9: Analysing data and undertaking meta-analysis. In: Higgins JPT, Green S, editor(s). Cochrane Handbook for Systematic Reviews of Interventions Version 5.1.0 (updated March 2011). The Cochrane Collaboration, 2011. Available from handbook.cochrane.org.

\section{Douketis 2012}

Douketis JD, Spyropoulos AC, Spencer FA, Mayr M, Jaffer AK, Eckman $\mathrm{MH}$, et al. Perioperative management of antithrombotic therapy: antithrombotic therapy and prevention of thrombosis, 9th ed: American College of Chest Physicians evidence-based clinical practice guidelines. Chest 2012;141(2 Suppl):e326S-50S. [PUBMED: 22315266]

\section{Forbes 1972}

Forbes CD, Barr RD, Reid G, Thomson C, Prentice CR, McNicol GP, et al. Tranexamic acid in control of haemorrhage after dental extraction in haemophilia and Christmas disease. British Medical Journal 1972;2(5809):311-3. [PUBMED: 4553818 ]

\section{Hanken 2016}

Hanken H, Grobe A, Heiland M, Smeets R, Kluwe L, Wikner J, et al. Postoperative bleeding risk for oral surgery under continued rivaroxaban anticoagulant therapy. Clinical Oral Investigations 2016;20(6):1279-82. [PUBMED: 26498769]

\section{Heidbuchel 2015}

Heidbuchel H, Verhamme P, Alings M, Antz M, Diener HC, Hacke W, et al. Updated European Heart Rhythm Association Practical Guide on the use of non-vitamin K antagonist anticoagulants in patients with non-valvular atrial fibrillation. Europace 2015;17(10):1467-507. [PUBMED: 26324838]

\section{Heidbüchel 2012}

Heidbüchel H, Beauloye C, Douxfils J, Goethals M, Hainaut $P$, Hermans $C$, et al. Rivaroxaban: a practical guide. www.thrombosisguidelinesgroup.be/sites/ default/files/Rivaroxaban\%20Practical\%20Guide \%20V1\%200_06-07-2012.pdf (accessed prior to 17 November 2017)

\section{Heidbüchel 2013}

Heidbüchel H, Thijs V, Verhamme P, Hermans C, Peeters A, Scavée C. Practical guide dabigatran: guidance for use in particular situations. http:// www.thrombosisguidelinesgroup.be/sites/default/files/ Dabigatran\%20practical\%20guide_Version\%202\%200_January \%202013.pdf (accessed prior to 17 November 2017).

\section{Higgins 2003}

Higgins JPT, Thompson SG, Deeks JJ, Altman DG. Measuring inconsistency in meta-analyses. BMJ 2003;327(7414):557-60.

Antifibrinolytic therapy for preventing oral bleeding in people on anticoagulants undergoing minor oral surgery or dental extractions 


\section{Higgins 2011a}

Higgins JPT, Deeks JJ, editor(s). Chapter 7: Selecting studies and collecting data. In: Higgins JPT, Green S, editor(s). Cochrane Handbook for Systematic Reviews of Interventions Version 5.1.0 (updated March 2011). The Cochrane Collaboration, 2011. Available from handbook.cochrane.org.

\section{Higgins 2011b}

Higgins JPT, Altman DG, Sterne JAC, editor(s) on behalf of the Cochrane Statistical Methods Group and the Cochrane Bias Methods Group. Chapter 8: Assessing risk of bias in included studies. In: Higgins JPT, Green S, editor(s). Cochrane Handbook for Systematic Reviews of Interventions. Version 5.1.0 (updated March 2011). The Cochrane Collaboration, 2011. Available from handbook.cochrane.org.

\section{Higgins 2011c}

Higgins JPT, Deeks JJ, Altman DG, editor(s) on behalf of the Cochrane Statistical Methods Group. Chapter 16: Special topics in statistics. In: Higgins JPT, Green S, editor(s). Cochrane Handbook of Systematic Reviews of Interventions. Version 5.1.0 (updated March 2011). The Cochrane Collaboration, 2011. Available from handbook.cochrane.org.

\section{Hussain 2017}

Hussain SS, Tyroch AH, Mukherjee D. Reversal of newer direct oral anticoagulant drugs (DOACS). Cardiovascular \& Hematological Agents in Medicinal Chemistry 2017; Vol. 14, issue 2:76-8. [PUBMED: 27215215]

\section{Liberati 2009}

Liberati A, Altman DG, Tetzlaff J, Mulrow C, Gotzsche PC, Ioannidis JP, et al. The PRISMA statement for reporting systematic reviews and meta-analyses of studies that evaluate health care interventions: explanation and elaboration. Journal of Clinical Epidemiology 2009;62(10):e1-34. [PUBMED: 19631507]

\section{McCormack 2012}

McCormack PL. Tranexamic acid: a review of its use in the treatment of hyperfibrinolysis. Drugs 2012;72(5):585-617. [PUBMED: 22397329]

\section{Mega 2015}

Mega JL, Simon T. Pharmacology of antithrombotic drugs: an assessment of oral antiplatelet and anticoagulant treatments. Lancet (London, England) 2015;386(9990):281-91. [PUBMED: 25777662]

\section{Olsen 2016}

Olsen JJ, Skov J, Ingerslev J, Thorn JJ, Pinholt EM. Prevention of bleeding in orthognathic surgery-a systematic review and metaanalysis of randomized controlled trials. Journal of Oral and Maxillofacial Surgery 2016;74(1):139-50. [PUBMED: 26073131]

\section{Palareti 1996}

Palareti G, Legnani C. Warfarin withdrawal. Pharmacokineticpharmacodynamic considerations. Clinical Pharmacokinetics 1996;30(4):300-13. [PUBMED: 8983860]

\section{Pell 1973}

Pell G. Tranexamic acid--its use in controlling dental postoperative bleeding in patients with defective clotting mechanisms. British Journal of Oral Surgery 1973;11(2):155-64. [PUBMED: 4274285]

\section{Perry 2007}

Perry DJ, Noakes TJ, Helliwell PS. Guidelines for the management of patients on oral anticoagulants requiring dental surgery. British Dental Journal 2007;203(7):389-93. [PUBMED: 17934422]

\section{Randall 2007}

Randall C. Surgical management of the primary care dental patient on warfarin. http://www.app.dundee.ac.uk/tuith/Static/ info/warfarin.pdf. North West Medicines Information Centre Pharmacy Practice Unit, Liverpool: United Kingdom medicines information, National Health Service, (accessed 27 June 2016). [PUBMED: 16178285]

\section{Randall 2015}

Randall C. New oral anticoagulants (NOACs) and management of dental patients - Dabigatran, rivaroxaban and apixaban. www.eryldc.co.uk/download/i/mark_dl/ u/4012071383/4615740784/New_oral_anticoagulants_and_ management_of_dental_patients_-_distribution__(Nov_2.pdf (accessed 27 June 2016).

\section{RefMan $^{\circledR} 2010$ [Computer program]}

Thomson Reuters. Reference Manager ${ }^{\circledast}$. Version 12 . Thomson Reuters, 2010.

\section{RevMan 2014 [Computer program]}

Nordic Cochrane Centre, The Cochrane Collaboration. Review Manager (RevMan). Version 5.3. Copenhagen: Nordic Cochrane Centre, The Cochrane Collaboration, 2014.

\section{Schünemann 2011a}

Schünemann HJ, Oxman AD, Higgins JPT, Vist GE, Glasziou P, Guyatt GH on behalf of the Cochrane Applicability and Recommendations Methods Group and the Cochrane Statistical Methods Group. Chapter 11: Presenting results and 'Summary of findings' tables. In: Higgins JPT, Green S, editor(s). Cochrane Handbook for Systematic Reviews of Interventions Version 5.1.0 (updated March 2011). The Cochrane Collaboration, 2011. Available from handbook.cochrane.org.

\section{Schünemann 2011b}

Schünemann HJ, Oxman AD, Vist GE, Higgins JPT, Deeks JJ, Glasziou P, et al on behalf of the Cochrane Applicability and Recommendations Methods Group and the Cochrane Statistical Methods Group. Chapter 12: Interpreting results and drawing conclusions. In: Higgins JPT, Green S, editor(s). Cochrane Handbook for Systematic Reviews of Interventions Version 5.1.0 (updated March 2011). The Cochrane Collaboration, 2011. Available from handbook.cochrane.org.

\section{Sime 2015}

Sime G, Armstrong C, Barker D, Brady A, Green P, Johnston S, et al. Management of dental patients taking anticoagulants or 
antiplatelet drugs. www.sdcep.org.uk/published-guidance/ anticoagulants-and-antiplatelets/ (accessed 27 June 2016).

\section{Sindet-Pedersen 1987}

Sindet-Pedersen S. Distribution of tranexamic acid to plasma and saliva after oral administration and mouth rinsing: a pharmacokinetic study. Journal of Clinical Pharmacology 1987;27(12):1005-8. [PUBMED: 3437064]

\section{Sindet-Pedersen 1990}

Sindet-Pedersen S, Gram J, Jespersen J. The possible role of oral epithelial cells in tissue-type plasminogen activatorrelated fibrinolysis in human saliva. Journal of Dental Research 1990;69(6):1283-6. [PUBMED: 2113068]

\section{van Galen 2015}

van Galen KP, Engelen ET, Mauser-Bunschoten EP, van Es RJ, Schutgens RE. Antifibrinolytic therapy for preventing oral bleeding in patients with haemophilia or Von Willebrand disease undergoing minor oral surgery or dental extractions. Cochrane Database of Systematic Reviews 2015, Issue 12. [DOI: 10.1002/14651858.CD011385.pub2]

\section{CHARACTERISTICS OF STUDIES}

Characteristics of included studies [ordered by study ID]

\section{Wahl 2000}

Wahl MJ. Myths of dental surgery in patients receiving anticoagulant therapy. Journal of the American Dental Association (1939) 2000;131(1):77-81. [PUBMED: 10649877]

\section{Yang 2016}

Yang S, Shi Q, Liu J, Li J, Xu J. Should oral anticoagulant therapy be continued during dental extraction? A meta-analysis. BMC Oral Health 2016;16(1):81. [PUBMED: 27566540]

\section{Zhao 2015}

Zhao B, Wang P, Dong Y, Zhu Y, Zhao H. Should aspirin be stopped before tooth extraction? A meta-analysis. Oral Surgery, Oral Medicine, Oral Pathology and Oral Radiology 2015;119(5):522-30. [PUBMED: 25767068]

\section{References to other published versions of this review Engelen 2016}

Engelen ET, Schutgens REG, Mauser-Bunschoten EP, van Es RJJ, van Galen KPM. Antifibrinolytic therapy for preventing oral bleeding in people on anticoagulants undergoing oral or dental procedures. Cochrane Database of Systematic Reviews 2016, Issue 8. [DOI: 10.1002/14651858.CD012293]

Blinder 1999

\begin{tabular}{|c|c|}
\hline Methods & $\begin{array}{l}\text { Trial design: quasi-RCT } \\
\text { Follow-up: } 7 \text { days }\end{array}$ \\
\hline Participants & $\begin{array}{l}\text { Country: Israel } \\
\text { Setting: Chaim Sheba Medical Center, Tel Aviv } \\
\text { Inclusion criteria: patients on anticoagulant treatment undergoing dental extraction(s) } \\
\text { Exclusion criteria: no exclusion criteria were reported } \\
\text { Sample size: } \\
\text { Control group 1: } \\
\text { - Total number of participants: } \mathrm{N}=50 \\
\text { - Total number of dental extractions: } 119 \\
\text { Control group 2: } \\
\text { - Total number of participants: } \mathrm{N}=50 \\
\text { - Total number of dental extractions: } \mathrm{N}=123 \\
\text { Intervention group (TXA): } \\
\text { - Total number of participants: } \mathrm{N}=50 \\
\text { - Total number of dental extractions: } \mathrm{N}=117 \\
\text { Participant characteristics: }\end{array}$ \\
\hline
\end{tabular}

Antifibrinolytic therapy for preventing oral bleeding in people on anticoagulants undergoing minor oral surgery or dental extractions 
Blinder 1999 (Continued)

\author{
- Age mean (range) years: TXA group (group 3): 64 (40 - 93) \\ Control group 1 (group 1): 56 (40 - 86) \\ Control group 2 (group 2): 61 (35 - 79) \\ - Sex N (M/F): 85/65 \\ - INR mean (range) TXA group (group 3): 2.19 (1.50 - 3.58) \\ Control group 1 (group 1): 2.38 (1.50 - 3.60) \\ Control group 2 (group 2): 2.7 (1.9 - 4)
}

\title{
Intervention group:
}

Resorbable gelatin sponge, sutures and TXA mouthwash $500 \mathrm{mg}$ rinsing $2 \mathrm{~min} 4 \mathrm{x}$ daily for a period of 4 days postoperatively, starting 24 hours after the procedure

\section{Control groups:}

Control group 1: resorbable gelatin sponge and sutures

Control group 2: resorbable gelatin sponge, sutures and fibrin glue (not eligible for inclusion)

Outcomes Number of postoperative bleeding episodes requiring intervention

Participants were considered to be "bleeding" when haemorrhage manifested one hour postextraction

Notes
Intervention groups eligible for the review:
- TXA group: gelatin sponge, sutures and TXA mouthwash
- Control group 1: gelatin sponge and sutures (standard care)
Intervention group not eligible for the review:
- Control group 2: gelatin sponge, sutures and fibrin glue

\section{Risk of bias}

Bias Authors' judgement Support for judgement

Random sequence genera- High risk "All patients treated on a particular day received the same procedure. The tion (selection bias) mode of local haemostasis was different for each day, as follows: Day 1. Resorbable gelatin sponge and multiple sutures (silk 000). Day 2. Resorbable gelatin sponge, multiple sutures (silk 000), and mouthwash with tranexamic acid $500 \mathrm{mg}$ for $2 \mathrm{~min}, 4$ times daily during a postoperative period of 4 days. Day 3. Fibrin glue, resorbable gelatin sponge, and multiple sutures (silk 000). This order was repeated throughout the study, until there were 50 patients in each group."

(Patients and methods, page 138)

\begin{tabular}{lll}
\hline $\begin{array}{l}\text { Allocation concealment } \\
\text { (selection bias) }\end{array}$ & High risk & See citation above \\
\hline $\begin{array}{l}\text { Blinding of participants } \\
\text { and personnel (perfor- } \\
\text { mance bias) }\end{array}$ & High risk & Trial is not blinded (see citation above) \\
All outcomes & &
\end{tabular}


Blinder 1999 (Continued)

Blinding of outcome as- High risk Trial is not blinded (see citation above) sessment (detection bias)

All outcomes

Incomplete outcome data Low risk All included participants were analysed
(attrition bias)

All outcomes

Selective reporting (re- Low risk $\quad$ All pre-specified outcome measures are reported for all trial participants
porting bias)

Other bias Unclear risk It is unclear whether participants could undergo multiple randomisations

Ramström 1993

Methods

Trial design: double-blind RCT

Follow up: 7 days

Participants Countries: Denmark and Sweden

Setting: oral surgery department of three hospitals: Karolinska Hospital and Huddinge Hospital in Stockholm, Sweden, and University Hospital in Aarhus, Denmark

\section{Inclusion criteria:}

Individuals on continuous, unchanged treatment with an oral anticoagulant (phenprocoumon, warfarin or dicoumarol)

- Older than 18 years

- Referred for tooth extraction (single or multiple), surgical removal of retained tooth (single or multiple), or endodontic surgery

- INR level within the therapeutic range ( $\geq 10 \%$ to $\leq 25 \%)$

\section{Exclusion criteria:}

- No informed consent

- Use of acetylsalicylic acid or nonsteroidal antiinflammatory agents within 14 days before surgery

- Indivduals known with haemorrhagic diathesis

\section{Sample size:}

TXA group:

- Total number of participant numbers: $\mathrm{N}=44$

- Mean (range) number of extracted teeth: $\mathrm{N}=1.5(0-5)$

- Mean (range) number of surgically treated teeth: $\mathrm{N}=1.6(1-5)$

Placebo group:

- Total number of participant numbers: $\mathrm{N}=45$

- Mean (range) number of extracted teeth: $\mathrm{N}=1.5(0-5)$

- Mean (range) number of surgically treated teeth: $\mathrm{N}=1.5(1-5)$ 
Ramström 1993 (Continued)

Numbers analysed/randomised:

- Safety analysis: $\mathrm{N}=93 / 93$

- Main efficacy evaluation: $\mathrm{N}=89 / 93$

7 participants participated in the study 2 or 3 times. The 93 participants included in the safety analysis represented 86 individuals, and the 89 participants included in the efficacy evaluation represented 82 individuals.

4 participants were excluded from the main efficacy analysis, 2 because of incorrect inclusion ( 1 on an anti-inflammatory agent and 1 subjected to an inappropriate type of surgery), and 2 because the first treatment period was not finished before the participant was included in a second

Participant characteristics:

- Age in years, mean (range): TXA group: 69.8 (53 - 87), placebo group: 67.1 (35 - 83)

- $\operatorname{Sex} N(M / F): 53 / 36$

- INR: 2.10 - 4.00

Interventions Intervention group:

Before suturing: irrigation with $10 \mathrm{~mL} 4.8 \%$ TXA solution

Postoperatively: rinsing with $10 \mathrm{~mL}$ TXA mouthwash for $2 \mathrm{~min} 4 \mathrm{x}$ daily for 7 days

Control group:

Before suturing: irrigation with $10 \mathrm{~mL}$ placebo solution

Postoperatively: placebo mouthwash for $2 \min 4 x$ daily for 7 days

1. Number of postoperative bleeding episodes requiring intervention
2. Side effects or other adverse events
3. Number of minor postoperative bleeding episodes (defined as self-limiting, usually with local pres-
sure, that does not require medical attention)
4. Any postoperative complication except bleeding, such as wound infection
5. Major bleeding, requiring transfusion of packed red blood cells
Bleeding was defined as postoperative bleeding that could not be controlled by compression with a
gauze pad for 20 min, with the participant sitting upright

Notes All intervention and control groups were eligible for the review

\section{Risk of bias}

\begin{tabular}{lll}
\hline Bias & Authors' judgement & Support for judgement \\
\hline $\begin{array}{ll}\text { Random sequence genera- } \\
\text { tion (selection bias) }\end{array}$ & Low risk & $\begin{array}{l}\text { "patients who met the inclusion criteria were randomised to either the tranex- } \\
\text { amic acid or placebo Group by the use of consecutively numbered medication } \\
\text { packages." } \\
\end{array}$ \\
& \\
& & \\
&
\end{tabular}

\begin{tabular}{ll}
\hline $\begin{array}{l}\text { Allocation concealment } \\
\text { (selection bias) }\end{array}$ & Low risk \\
& $\begin{array}{l}\text { about the randomisation code for each patient, to be opened in case of emer- } \\
\text { gency, were prepared by Kabi Pharmacia." }\end{array}$
\end{tabular}

Antifibrinolytic therapy for preventing oral bleeding in people on anticoagulants undergoing minor oral surgery or dental extractions 


$\begin{array}{ll}\text { Blinding of participants } \quad \text { Low risk } & \text { "The investigation was a randomised, double-blind, placebo-controlled, multi- } \\ \text { and personnel (perfor- } & \text { center study." }\end{array}$

mance bias)

All outcomes

(Abstract, page 1211)

"Active solution, $10 \mathrm{~mL}$, containing 4.8\% tranexamic acid and an apparently identical placebo solution, also produced by Kabi Pharmacia, were used."

(Materials and Methods, page 1212)

\begin{tabular}{|c|c|c|}
\hline $\begin{array}{l}\text { Blinding of outcome as- } \\
\text { sessment (detection bias) } \\
\text { All outcomes }\end{array}$ & Unclear risk & This is not clearly discussed in the article \\
\hline $\begin{array}{l}\text { Incomplete outcome data } \\
\text { (attrition bias) } \\
\text { All outcomes }\end{array}$ & Low risk & $\begin{array}{l}\text { No loss to follow-up: the results of all participants are reported. Reasons for } \\
\text { excluding } 4 \text { participants from the main efficacy analysis after randomisation } \\
\text { are also included in the results section } \\
\text { (Results, page } 1213-5 \text { ) }\end{array}$ \\
\hline $\begin{array}{l}\text { Selective reporting (re- } \\
\text { porting bias) }\end{array}$ & Low risk & All pre-specified outcome measures are reported for all trial participants \\
\hline Other bias & Low risk & $\begin{array}{l}\text { Multiple randomisations: "Seven participants participated in the study two } \\
\text { or three times." (Results, page 1213). Considered as low risk of bias, as partici- } \\
\text { pants were blinded }\end{array}$ \\
\hline
\end{tabular}

Sindet-Pedersen 1989

\begin{tabular}{ll} 
Methods & Trial design: double-blind RCT \\
& Follow up: 7 days \\
\hline
\end{tabular}

\section{Participants}

\section{Countries: Denmark and Sweden}

Setting: 2 hospitals: Aarhus University Hospital in Aarhus, Denmark, and Karolinska Hospital in Stockholm, Sweden

\section{Inclusion criteria:}

Individuals with a cardiac-valve stenosis, a cardiac-valve prosthesis or a vascular prosthesis on oral anticoagulant treatment at a therapeutic level

- who were to undergo oral surgery

- PP between $10 \%$ - $20 \%$ or TT result between $5 \%$ - 12\%

(USA: PT ratio of 1.4-2.0 or an INR level between 2.5 - 4.8)

\section{Exclusion criteria:}

- No informed consent

- Use of aspirin and other antiinflammatory drugs in the 2 weeks before surgery

\section{Sample size:}

TXA group: 
Sindet-Pedersen 1989 (Continued)

- Total number of participants: $\mathrm{N}=19$

- Mean number of surgically treated teeth per participant: $N=3.3$

Placebo group:

- Total number of participants: $\mathrm{N}=20$

- Mean number of surgically treated teeth per participant: 2.8

Numbers analysed/randomised:

- Total: $N=39 / 39$

\section{Participant characteristics:}

- Age (mean, range): TXA group: Aarhus 56.3 years (20 - 72), Stockholm mean 59.7 (47 - 69); placebo group: Aarhus 48.7 years (19-65), Stockholm 62.6 years $(38-77)$

$-\operatorname{Sex} N(M / F): N=22 / 17$

- INR PP between $10 \%$ - $20 \%$ or TT result between $5 \%-12 \%$

(USA: PT ratio of $1.4-2.0$ or an INR of $2.5-4.8$ )

Before suturing: irrigation with $10 \mathrm{~mL} 4.8 \%$ TXA solution

Postoperatively: rinsing with $10 \mathrm{~mL}$ TXA mouthwash for $2 \mathrm{~min} 4 \mathrm{x}$ daily for 7 days

\section{Control group:}

Before suturing: irrigation with $10 \mathrm{~mL}$ placebo solution

Postoperatively: placebo mouthwash for $2 \min 4 x$ daily for 7 days

1. Number of postoperative bleeding episodes requiring intervention
2. Side effects or other adverse events
$\begin{aligned} & \text { 3. Number of minor postoperative bleeding episodes (defined as self-limiting, usually with local pres- } \\ & \text { sure, that does not require medical attention) } \\ & \text { 4. Major bleeding, requiring transfusion of packed red blood cells } \\ & \text { Bleeding was defined as postoperative bleeding that could not be controlled by compression with } \\ & \text { gauze for } 20 \text { min }\end{aligned}$

Notes All intervention and control groups were eligible for the review

\section{Risk of bias}

\section{Bias}

Authors' judgement Support for judgement

Random sequence genera- Low risk tion (selection bias)

"Random numbers were used to assign consecutive patients to treatment groups."

(Methods, page 841)
Allocation concealment Low risk (selection bias)

\begin{abstract}
"Random numbers were used to assign consecutive patients to treatment groups. Each number corresponded to a medication package with 28 bottles, each containing $10 \mathrm{~mL}$ of one of the solutions. Randomization was carried out independently for each of the clinics."
\end{abstract}


(Methods, page 841)

\section{Blinding of participants Low risk} and personnel (perfor-

mance bias)

All outcomes

"The study was carried out as a double-blind investigation with parallel groups, comparing the hemostatic effect of a sterile aqueous solution of 4.8 percent tranexamic acid used as a mouthwash with that of a placebo solution

(Methods, page 841)

Participants followed the same treatment schedule.

"Before sutures were applied, the operative field was irrigated with $10 \mathrm{ml}$ of the test solution. After surgery, the patients were instructed to rinse their mouths with $10 \mathrm{ml}$ of the assigned solution for two minutes and then to expectorate the solution (four times a day for seven days)."

(Methods, page 841)

Blinding of outcome as- Unclear risk This was not clearly discussed in the article
sessment (detection bias)

All outcomes

\section{Incomplete outcome data Low risk} (attrition bias)

All outcomes

"Forty-five patients were recruited..." "...Six patients did not meet the requirements for inclusion. Thus, 39 patients were eligible for further analysis."

(Methods, page 841)

Selective reporting (re- Low risk $\quad$ All pre-specified outcome measures are reported for all trial participants
porting bias)

Other bias Unclear risk It is unclear whether participants could undergo multiple randomisations

Soares 2015

Methods

\section{Trial design: RCT}

Follow up: 7 days

\section{Participants}

Country: Brazil

Setting: single centre, Federal University of Ceará

Inclusion criteria:

- People using warfarin

- Requiring extractions of at least 2 teeth

- Minimum age of 18 years

\section{Exclusion criteria:}

- Use of associated anticoagulating medications (other than warfarin)

- Smokers, pregnant or lactating women

- Reported pre-existing blood dyscrasias

- Individuals who did not return for reassessment were removed from the trial

Antifibrinolytic therapy for preventing oral bleeding in people on anticoagulants undergoing minor oral surgery or dental extractions 
- Surgical sites subjected to procedures requiring mucoperiosteal flap for dental extractions or that lasted longer than $30 \mathrm{~min}$ were not included in the study sample

\section{Sample size:}

TXA group:

- Total number of surgical procedures: 28

- Total number of participants: 12

Fibrin sponge group:

- Total number of surgical procedures: 28

- Total number of participants: 13

Control group (dry gauze):

- Total number of surgical procedures: 28

- Total number of participants: 13

Number of individuals analysed/randomised:

- Total number of surgical procedures analysed/randomised: 84/93

- TXA group: 28/33

- Fibrin sponge group: 28/32

- Control group (dry gauze): $28 / 28$

\section{Participant characteristics:}

- Age in years (mean (SD)) TXA group: 51.0 (2.9); fibrin sponge group: 51.1 (3.3); control group (dry gauze): $51.1(2.8)$

- $\operatorname{Sex}(M / F): N=22 / 16$

- Mean (SD) INR: TXA group: 2.52 (0.16); fibrin sponge group: 2.51 (0.16); control group (dry gauze): 2.51 (0.13)

\section{Intervention group 1:}

Gauze pad soaked in 4.8\% TXA was applied to the surgical alveolus for 8 min under biting pressure

\section{Intervention group 2}

Fibrin sponge was packed into the surgical alveolus, and the individual was asked to bite down on the gauze for $8 \mathrm{~min}$ for compression

\section{Control group:}

Dry gauze compression was performed under biting pressure on the surgical alveolus for 8 min without the use of local haemostatic agents

\section{All groups:}

Surgical sites were occluded with suture in "X" fashion (silk 4.0)

Only 1 tooth was extracted per appointment 
Soares 2015 (Continued)

Postoperative bleeding was defined as bleeding on the extraction site that could not be controlled by gauze compression during $20 \mathrm{~min}$ and/or requiring medical intervention

\begin{tabular}{ll}
\hline Notes & Intervention and control groups eligible for the review: \\
& - Intervention group 1: gauze pad soaked in 4.8\% TXA \\
& - Control group: dry gauze compression \\
& Intervention groups not eligible for the review: \\
- Intervention group 2: fibrin sponge
\end{tabular}

\section{Risk of bias}

Bias Authors' judgement Support for judgement

Random sequence genera- Low risk tion (selection bias)

"Extraction sites were considered as sampling units and, according to the local haemostatic procedure to be performed, were randomly allocated into one of the three study groups by using a computer-generated code:..."

(Patients and methods, page 210)

Allocation concealment $\quad$ Unclear risk
(selection bias)

$\begin{array}{ll}\text { Blinding of participants } & \text { High risk } \\ \begin{array}{l}\text { and personnel (perfor- } \\ \text { mance bias) }\end{array} & \text { The performance of the interventions was not blinded } \\ \text { All outcomes } & \text { (Patients and methods, page 211) }\end{array}$

\begin{tabular}{|c|c|c|}
\hline $\begin{array}{l}\text { Blinding of outcome as- } \\
\text { sessment (detection bias) } \\
\text { All outcomes }\end{array}$ & Low risk & $\begin{array}{l}\text { "The investigator who contacted the study participants for the purpose of } \\
\text { evaluating bleeding complications was blinded to the haemostatic protocol al- } \\
\text { location throughout the study period" } \\
\text { (Patients and methods, page 212) }\end{array}$ \\
\hline $\begin{array}{l}\text { Incomplete outcome data } \\
\text { (attrition bias) } \\
\text { All outcomes }\end{array}$ & Low risk & $\begin{array}{l}\text { Loss to follow-up of three participants ( } N=9 \text { surgical procedures), however the } \\
\text { percentage of participants that were lost to follow-up was less than } 10 \%\end{array}$ \\
\hline $\begin{array}{l}\text { Selective reporting (re- } \\
\text { porting bias) }\end{array}$ & Low risk & All pre-specified outcome measures are reported for all trial participants \\
\hline Other bias & High risk & $\begin{array}{l}\text { Participants were randomised more than once. Considered as high risk of bias, } \\
\text { as participants were not blinded }\end{array}$ \\
\hline
\end{tabular}

INR: international normalised ratio

$\mathrm{RCT}$ : randomised controlled trial

SD: standard deviation

TXA: tranexamic acid

Characteristics of excluded studies [ordered by study ID]

\begin{tabular}{ll}
\hline Study & Reason for exclusion \\
\hline Borea 1993 & Inadequate comparison group (lower dose of anticoagulant) \\
\hline
\end{tabular}

Antifibrinolytic therapy for preventing oral bleeding in people on anticoagulants undergoing minor oral surgery or dental extractions 


\begin{tabular}{|c|c|}
\hline Study & Reason for exclusion \\
\hline Bublitz 2000 & Lack of (quasi-)randomisation \\
\hline Bucciarelli 1997 & No adequate comparison \\
\hline Carter 2003 & No adequate comparison \\
\hline Chow 2003 & Editor's correspondence, not a clinical trial \\
\hline Gaspar 1997 & Does not meet inclusion criteria (inadequate study design and comparison) \\
\hline Goss 2002 & Letter to the editor \\
\hline Hoppe 1969 & Does not meet the inclusion criteria (inadequate trial design, intervention groups and outcomes) \\
\hline Keiani 2003 & Not a randomised controlled trial (prospective cohort study) \\
\hline Kwapis 1963 & Does not meet the inclusion criteria (inadequate trial design and intervention groups) \\
\hline Mclntyre 1966 & Does not meet inclusion criteria (inadequate trial design and intervention groups) \\
\hline Sammartino 2012 & No treatment with vitamin $\mathrm{K}$ antagonists (antiplatelet therapy) and no adequate comparison \\
\hline Somma 2010 & Does not meet inclusion criteria (inadequate trial design and no comparison group) \\
\hline Souto 1996 & No comparison group without TXA or EACA \\
\hline Timocin 1996 & $\begin{array}{l}\text { Inadequate trial design ( } 2 \text { groups, but does not state randomisation used, no response from multi- } \\
\text { ple contacts made to author team) }\end{array}$ \\
\hline
\end{tabular}

EACA: epsilon aminocaproic acid

TXA: tranexamic acid

Characteristics of ongoing studies [ordered by study ID]

\section{EXTRACT-NOAC 2018}

Trial name or title EXTRACT-NOAC

Acronym of 'Tranexamic Acid To Reduce Bleeding in Patients Treated with New Oral Anticoagulants Undergoing Dental Extraction'

\begin{tabular}{ll}
\hline Methods & Prospective, randomised, double-blind, placebo-controlled, multicentre, phase IV, clinical trial \\
\hline Participants & People taking NOACs and undergoing tooth extractions \\
\hline Interventions & $\begin{array}{l}\text { To analyse whether adding TXA 10\% mouthwash to standard-of-care procedures decreases the } \\
\text { number of post-extraction bleeding events in people taking NOACs. Since topical application of TXA } \\
\text { results in minimal systemic absorption, TXA mouthwash may reduce postextraction bleeding with- } \\
\text { out systemic effects. Therefore, TXA is an attractive and effective local haemostatic agent. The tri- } \\
\text { al is being performed in view of drafting guidelines concerning the postoperative management of } \\
\text { people treated with NOACs and undergoing tooth extractions. In this way, the postoperative care of } \\
\text { this participant group can be assured and will improve }\end{array}$
\end{tabular}

Outcomes

Post-extraction bleeding events 
EXTRACT-NOAC 2018 (Continued)

\begin{tabular}{ll} 
Starting date & 01 September 2017 \\
\hline Contact information & anna.ockerman@kuleuven.be \\
\hline Notes & Duration 4 years
\end{tabular}

NOACs: new oral anticoagulants

TXA: tranexamic acid

\section{DATA AND ANALYSES}

\section{Comparison 1. Antifibrinolytic therapy versus placebo or standard care}

\begin{tabular}{|c|c|c|c|c|}
\hline Outcome or subgroup title & No. of studies & $\begin{array}{l}\text { No. of partici- } \\
\text { pants }\end{array}$ & Statistical method & Effect size \\
\hline $\begin{array}{l}1 \text { Number of people with postopera- } \\
\text { tive bleedings }\end{array}$ & 4 & 253 & $\begin{array}{l}\text { Risk Difference (M-H, Ran- } \\
\text { dom, } 95 \% \mathrm{Cl})\end{array}$ & $-0.13[-0.30,0.05]$ \\
\hline 1.1 Control group: placebo & 2 & 128 & $\begin{array}{l}\text { Risk Difference (M-H, Ran- } \\
\text { dom, } 95 \% \mathrm{Cl})\end{array}$ & $-0.25[-0.36,-0.14]$ \\
\hline 1.2 Control group: Standard care & 2 & 125 & $\begin{array}{l}\text { Risk Difference (M-H, Ran- } \\
\text { dom, } 95 \% \mathrm{Cl})\end{array}$ & $0.02[-0.07,0.11]$ \\
\hline $\begin{array}{l}2 \text { Number of side effects requiring } \\
\text { withdrawal }\end{array}$ & 2 & 128 & $\begin{array}{l}\text { Risk Difference (M-H, Ran- } \\
\text { dom, } 95 \% \mathrm{Cl})\end{array}$ & $0.0[-0.04,0.04]$ \\
\hline $\begin{array}{l}3 \text { Number of people with minor post- } \\
\text { operative bleedings }\end{array}$ & 2 & 128 & $\begin{array}{l}\text { Risk Difference (M-H, Ran- } \\
\text { dom, } 95 \% \mathrm{Cl})\end{array}$ & $-0.06[-0.33,0.20]$ \\
\hline $\begin{array}{l}4 \text { Number of immediate and delayed } \\
\text { postoperative bleedings }\end{array}$ & 1 & & $\begin{array}{l}\text { Risk Difference (M-H, Ran- } \\
\text { dom, } 95 \% \mathrm{Cl})\end{array}$ & $\begin{array}{l}\text { Totals not select- } \\
\text { ed }\end{array}$ \\
\hline $\begin{array}{l}5 \text { Number of people with complica- } \\
\text { tions other than bleeding, such as } \\
\text { wound infection }\end{array}$ & 2 & 128 & $\begin{array}{l}\text { Risk Difference (M-H, Ran- } \\
\text { dom, } 95 \% \mathrm{Cl})\end{array}$ & $-0.02[-0.07,0.03]$ \\
\hline $\begin{array}{l}6 \text { Number of people with bleeding } \\
\text { requiring transfusion of packed red } \\
\text { blood cells }\end{array}$ & 4 & 253 & $\begin{array}{l}\text { Risk Difference (M-H, Ran- } \\
\text { dom, } 95 \% \mathrm{Cl})\end{array}$ & $-0.00[-0.03,0.03]$ \\
\hline 6.1 Control group: Placebo & 2 & 128 & $\begin{array}{l}\text { Risk Difference (M-H, Ran- } \\
\text { dom, } 95 \% \mathrm{Cl})\end{array}$ & $-0.00[-0.05,0.04]$ \\
\hline 6.2 Control group: Standard care & 2 & 125 & $\begin{array}{l}\text { Risk Difference (M-H, Ran- } \\
\text { dom, } 95 \% \mathrm{Cl})\end{array}$ & $0.0[-0.04,0.04]$ \\
\hline
\end{tabular}


Analysis 1.1. Comparison 1 Antifibrinolytic therapy versus placebo or standard care, Outcome 1 Number of people with postoperative bleedings.

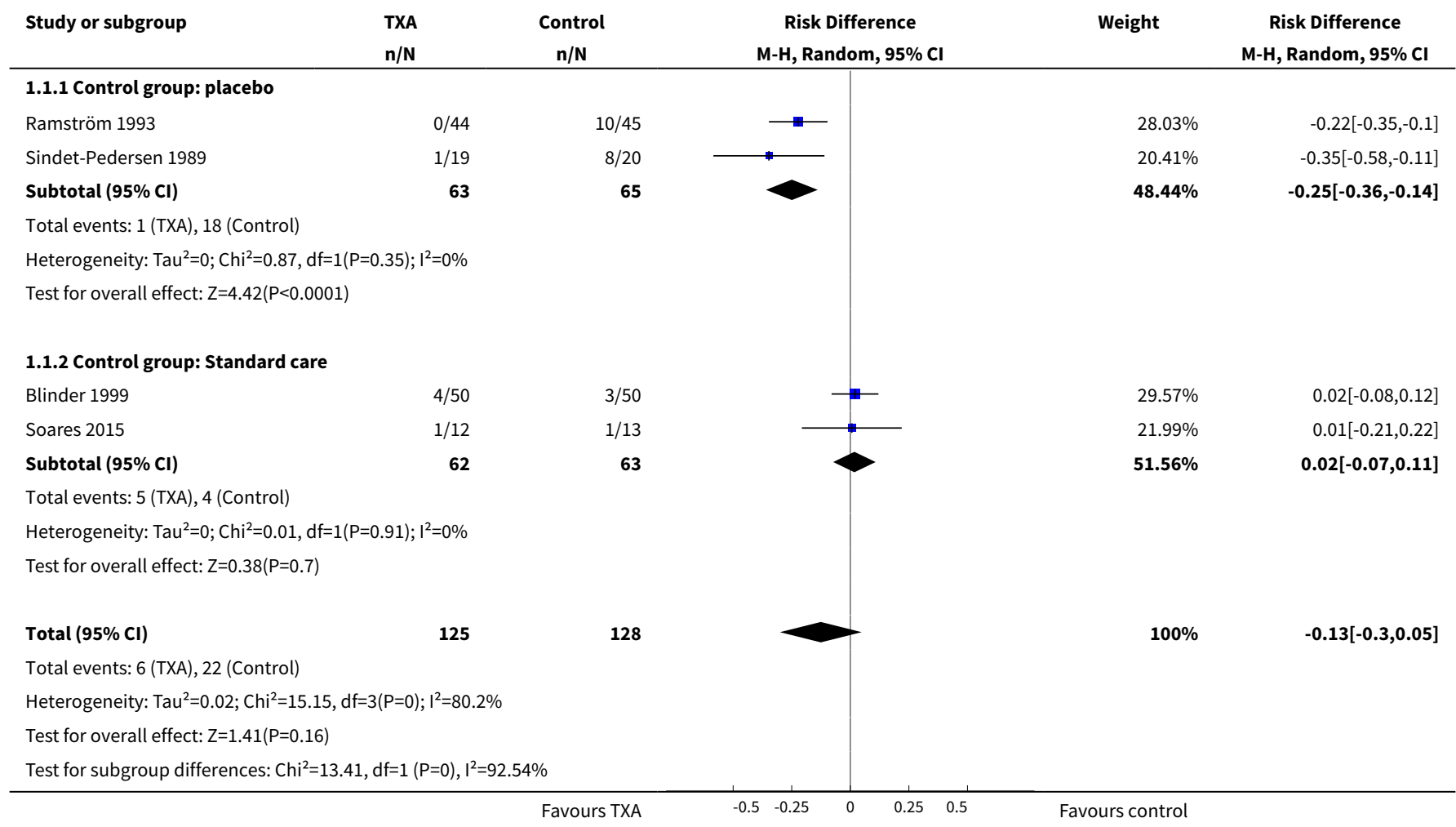

Analysis 1.2. Comparison 1 Antifibrinolytic therapy versus placebo or standard care, Outcome 2 Number of side effects requiring withdrawal.

\begin{tabular}{|c|c|c|c|c|c|}
\hline Study or subgroup & $\begin{array}{l}\text { TXA } \\
\mathrm{n} / \mathrm{N}\end{array}$ & $\begin{array}{c}\text { Control } \\
\mathrm{n} / \mathrm{N}\end{array}$ & $\begin{array}{c}\text { Risk Difference } \\
\text { M-H, Random, 95\% CI }\end{array}$ & Weight & $\begin{array}{c}\text { Risk Difference } \\
\text { M-H, Random, } 95 \% \mathrm{Cl}\end{array}$ \\
\hline Ramström 1993 & $0 / 44$ & $0 / 45$ & - & $82.95 \%$ & $0[-0.04,0.04]$ \\
\hline Sindet-Pedersen 1989 & $0 / 19$ & $0 / 20$ & & $17.05 \%$ & $0[-0.09,0.09]$ \\
\hline Total $(95 \% \mathrm{Cl})$ & 63 & 65 & & $100 \%$ & $0[-0.04,0.04]$ \\
\hline \multicolumn{6}{|c|}{ Total events: 0 (TXA), 0 (Control) } \\
\hline \multicolumn{6}{|c|}{ Test for overall effect: Not applicable } \\
\hline & & Favours TXA & $-0.2-0.1$ & control & \\
\hline
\end{tabular}

Analysis 1.3. Comparison 1 Antifibrinolytic therapy versus placebo or standard care, Outcome 3 Number of people with minor postoperative bleedings.

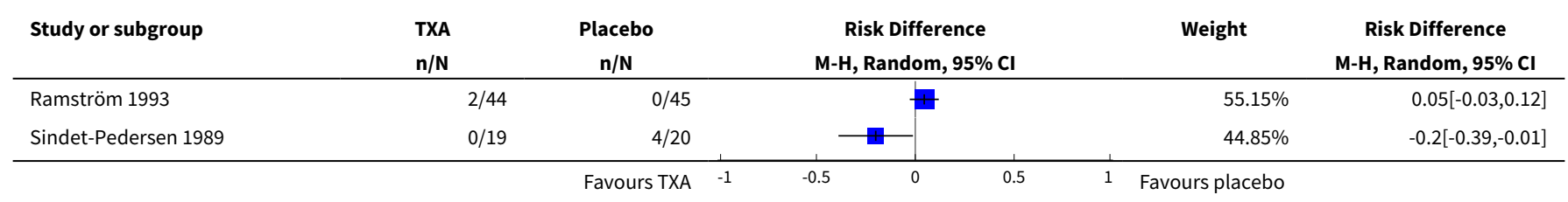




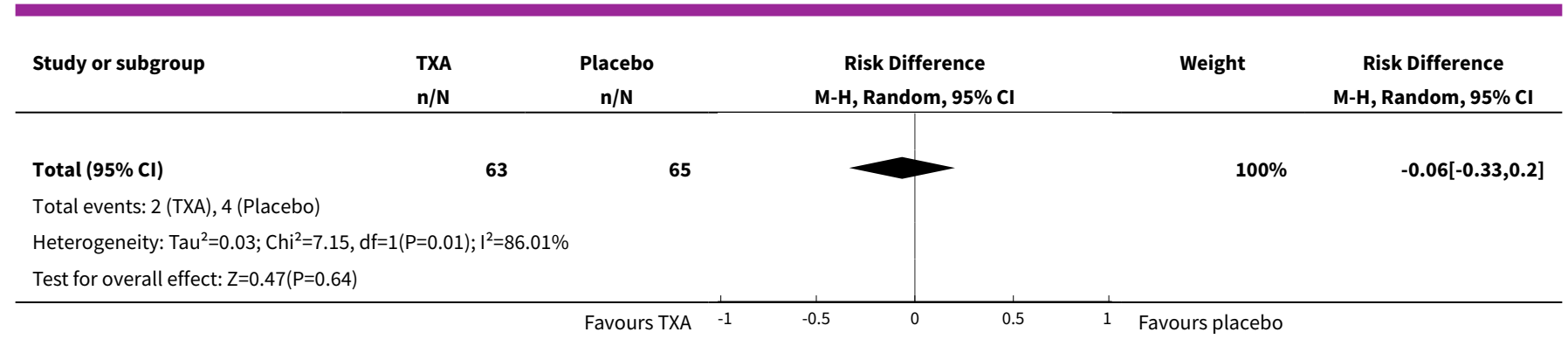

Analysis 1.4. Comparison 1 Antifibrinolytic therapy versus placebo or standard care, Outcome 4 Number of immediate and delayed postoperative bleedings.

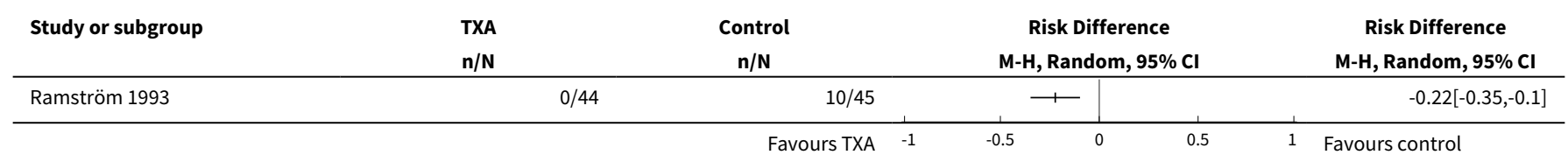

Analysis 1.5. Comparison 1 Antifibrinolytic therapy versus placebo or standard care, Outcome 5 Number of people with complications other than bleeding, such as wound infection.

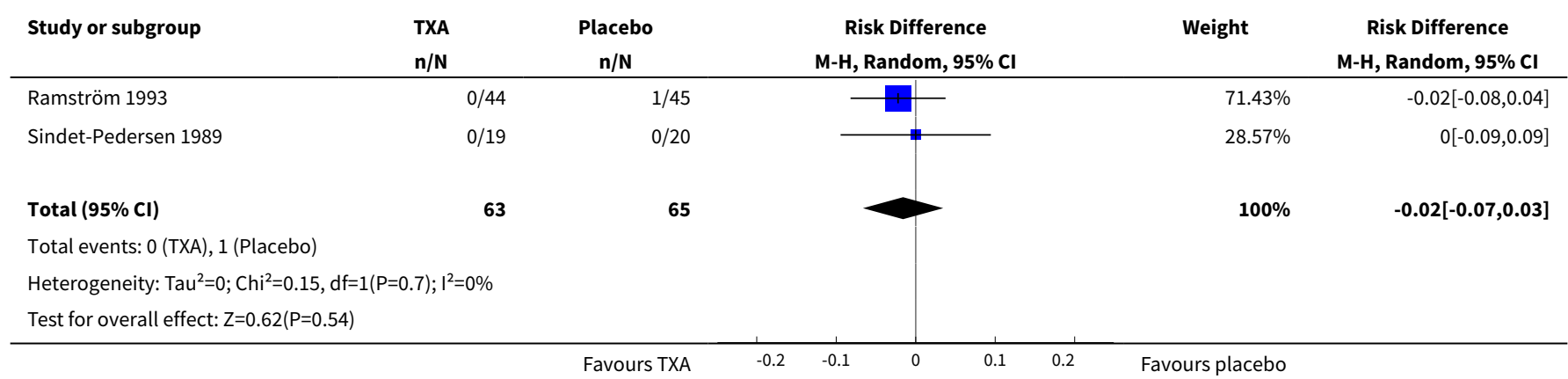

Analysis 1.6. Comparison 1 Antifibrinolytic therapy versus placebo or standard care, Outcome 6 Number of people with bleeding requiring transfusion of packed red blood cells.

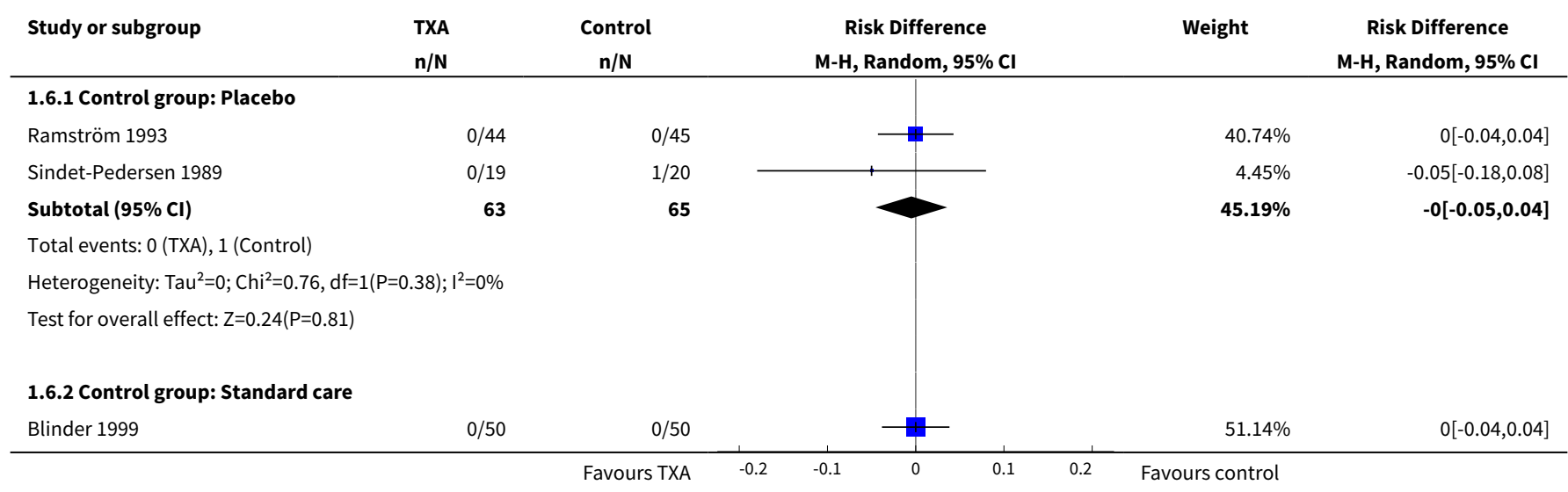

Antifibrinolytic therapy for preventing oral bleeding in people on anticoagulants undergoing minor oral surgery or dental extractions 


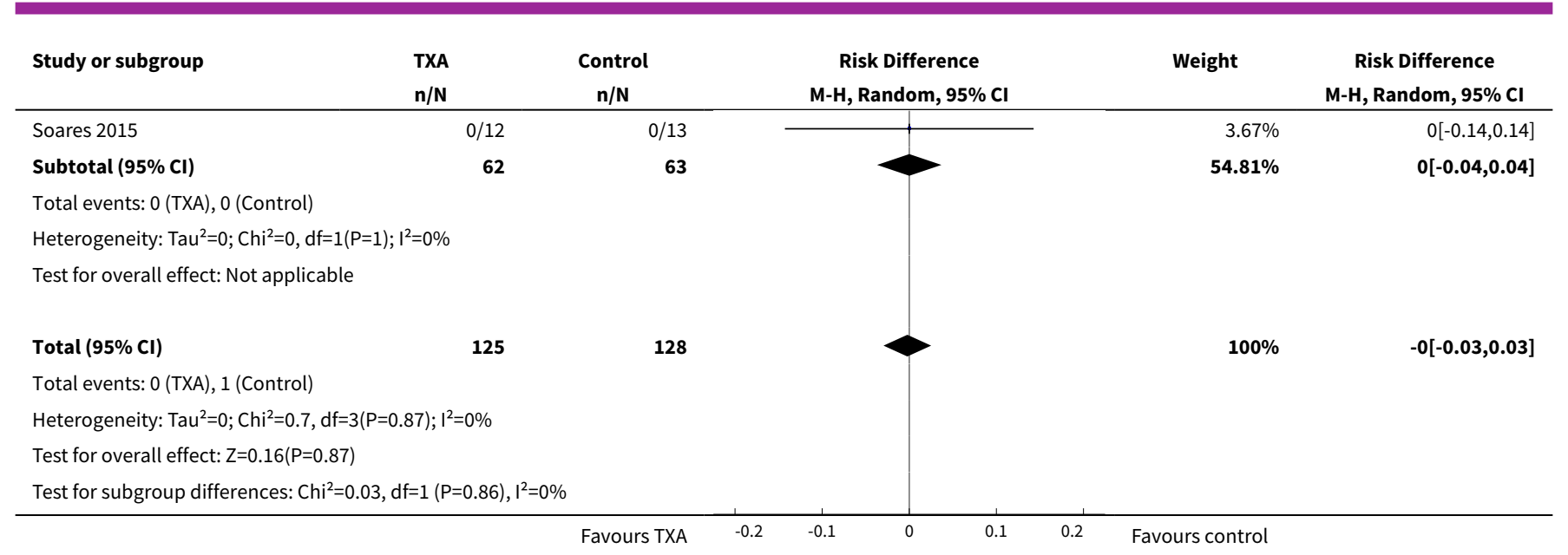

\section{APPENDICES}

\section{Appendix 1. Search strategies}

\section{Cochrane Central Register of Controlled Trials (CENTRAL) and Cochrane Database of Systematic Reviews (CDSR)}

[Advanced Search - Search Manager form]

\#1 ("oral surgery":ti,ab OR “oral surgical procedures":ti,ab OR dental:ti,ab OR tooth:ti,ab OR "operative dentistry":ti,ab OR molar:ti,ab OR dentoalveolar:ti,ab OR orthognathic:ti,ab OR periodontal:ti,ab)

\#2 (anticoagulants:ti,ab OR anticoagulant:ti,ab OR anticoagulation:ti,ab OR anticoagulated:ti,ab OR "vitamin k antagonist":ti,ab OR "antivitamin k":ti,ab OR "antivitamin k":ti,ab OR "anti vitamin k":ti,ab OR (acquired AND coagul*:ti,ab) OR VKA:ti,ab OR warfarin:ti,ab OR phenprocoumon:ti,ab OR acenocoumarol:ti,ab OR coumadin:ti,ab OR coumadins:ti,ab OR coumarin:ti,ab OR coumarins:ti,ab OR "new oral anticoagulant":ti,ab OR "newer oral anticoagulant":ti,ab OR NOAC:ti,ab OR "non-vitamin k antagonist":ti,ab OR "non-vitamin-kantagonist”:ti,ab OR “non-vitamin k dependent antagonist”:ti,ab OR DOAC:ti,ab OR “direct oral anticoagulant":ti,ab)

\#3 (antifibrinolytic:ti,ab OR tranexamic:ti,ab OR cyclokapron:ti,ab OR cyklokapron:ti,ab OR eaca:ti,ab OR “aminocaproic acid":ti,ab OR amicar:ti,ab OR TXA:ti,ab)

\#4 \#1 AND \#2 AND \#3

\section{PubMed (1946 onwards)}

\#1 ("surgery, oral"[MeSH Terms] OR "oral surgical procedures"[MeSH Terms] OR "tooth extraction"[MeSH Terms] OR "Dentistry, Operative"[MeSH] OR "molar"[MeSH Terms] OR "oral surgery"[tiab] OR "oral surgical procedures"[tiab] OR dental[tiab] OR tooth[tiab] OR "operative dentistry"[tiab] OR molar[tiab] OR dentoalveolar[tiab] OR orthognathic[tiab] OR periodontal[tiab])

\#2 ("anticoagulants"[MeSH Terms] OR "anticoagulants"[Pharmacological Action] OR "warfarin"[MeSH Terms] OR "phenprocoumon"[MeSH Terms] OR "acenocoumarol"[MeSH Terms] OR "coumarins"[MeSH Terms] OR anticoagulants[tiab] OR anticoagulant[tiab] OR anticoagulation[tiab] OR anticoagulated[tiab] OR “vitamin k antagonist"[tiab] OR "anti-vitamin k"[tiab] OR "antivitamin k"[tiab] OR "anti vitamin k"[tiab] OR (acquired AND coagul*[tiab]) OR VKA[tiab] OR warfarin[tiab] OR phenprocoumon[tiab] OR acenocoumarol[tiab] OR coumadin[tiab] OR coumadins[tiab] OR coumarin[tiab] OR coumarins[tiab] OR "new oral anticoagulant"[tiab] OR "newer oral anticoagulant"[tiab] OR NOAC[tiab] OR "non-vitamin k antagonist"[tiab] OR "non-vitamin-k-antagonist"[tiab] OR "nonvitamin k dependent antagonist"[tiab] OR DOAC[tiab] OR "direct oral anticoagulant"[tiab])

\#3 ("antifibrinolytic agents"[MeSH Terms] OR "antifibrinolytic agents"[Pharmacological Action] OR "tranexamic acid"[MeSH Terms] OR "aminocaproic acid"[MeSH Terms] OR antifibrinolytic[tiab] OR tranexamic[tiab] OR cyclokapron[tiab] OR cyklokapron[tiab] OR eaca[tiab] OR “aminocaproic acid”[tiab] OR amicar[tiab] OR TXA[tiab])

\#4 1 AND 2 AND 3

Antifibrinolytic therapy for preventing oral bleeding in people on anticoagulants undergoing minor oral surgery or dental extractions 


\section{Embase Platform}

\#1 ('oral surgery'/exp OR 'dental procedure'/exp OR 'tooth'/exp OR 'orthognathic surgery'/exp OR 'oral surgery':ti,ab OR 'oral surgical procedures':ti,ab OR dental:ti,ab OR tooth:ti,ab OR dentoalveolar:ti,ab OR orthognathic:ti,ab)

\#2 ('anticoagulant agent'/exp OR 'anticoagulation'/exp OR 'anticoagulant therapy'/exp OR 'coumarin derivative'/exp OR anticoagulation:ti,ab OR anticoagulant:ti,ab OR anticoagulants:ti,ab OR anticoagulated:ti,ab OR 'vitamin k antagonist':ti,ab OR 'antivitamin k':ti,ab OR 'antivitamin k':ti,ab OR 'anti vitamin k':ti,ab OR (acquired AND coagul*:ti,ab) OR vka:ti,ab OR warfarin:ti,ab OR phenprocoumon:ti,ab OR acenocoumarol:ti,ab OR coumarin:ti,ab OR coumarins:ti,ab OR coumadin:ti,ab OR coumadins:ti,ab OR 'new oral anticoagulant':ti,ab OR 'newer oral anticoagulant':ti,ab OR NOAC:ti,ab OR 'non-vitamin k antagonist':ti,ab OR 'non-vitamin-kantagonist':ti,ab OR 'non-vitamin k dependent antagonist':ti,ab OR DOAC:ti,ab OR 'direct oral anticoagulant':ti,ab)

\#3 ('antifibrinolytic agent'/exp OR 'antifibrinolytic':ti,ab OR tranexamic:ti,ab OR 'aminocaproic acid':ti,ab OR cyclokapron:ti,ab OR cyklokapron:ti,ab OR eaca:ti,ab OR amicar:ti,ab OR txa:ti,ab)

\#4 \#1 AND \#2 AND \#3

\section{CINAHL Platform EBSCO}

\#1 TI (antifibrinolytic OR tranexamic OR cyclokapron OR cyklokapron OR eaca OR "aminocaproic acid" OR amicar OR TXA) OR AB (antifibrinolytic OR tranexamic OR cyclokapron OR cyklokapron OR eaca OR “aminocaproic acid” OR amicar OR TXA)

\#2 TI (anticoagulants OR anticoagulant OR anticoagulation OR anticoagulated OR "vitamin k antagonist" OR "anti-vitamin k" OR "antivitamin k" OR "anti vitamin k" OR (acquired AND coagul ${ }^{\star}$ ) OR VKA OR warfarin OR phenprocoumon OR acenocoumarol OR coumadin OR coumadins OR coumarin OR coumarins OR "new oral anticoagulant" OR "newer oral anticoagulant" OR NOAC OR "non-vitamin k antagonist" OR "non-vitamin-k-antagonist" OR "non-vitamin k dependent antagonist" OR DOAC OR "direct oral anticoagulant") OR AB (anticoagulants OR anticoagulant OR anticoagulation OR anticoagulated OR "vitamin k antagonist" OR "anti-vitamin k" OR "antivitamin k" OR "anti vitamin k" OR (acquired AND coagul*) OR VKA OR warfarin OR phenprocoumon OR acenocoumarol OR coumadin OR coumadins OR coumarin OR coumarins OR "new oral anticoagulant" OR "newer oral anticoagulant" OR NOAC OR "non-vitamin k antagonist" OR "nonvitamin-k-antagonist" OR "non-vitamin k dependent antagonist" OR DOAC OR "direct oral anticoagulant")

\#3 TI (antifibrinolytic OR tranexamic OR cyclokapron OR cyklokapron OR eaca OR "aminocaproic acid" OR amicar OR TXA) OR AB (antifibrinolytic OR tranexamic OR cyclokapron OR cyklokapron OR eaca OR “aminocaproic acid” OR amicar OR TXA)

\#4 \#1 AND \#2 AND \#3

\section{PQDT Open}

(oral surgery OR dental OR tooth OR periodontal) AND (anticoagulant OR anticoagulation OR vitamin k antagonist OR VKA OR (acquired AND coagul $^{\star}$ ) OR new oral anticoagulant OR NOAC OR direct oral anticoagulant OR DOAC) AND (antifibrinolytic OR tranexamic OR cyclokapron OR cyklokapron OR eaca OR aminocaproic acid OR amicar OR TXA)

\section{ClinicalTrials.gov (no restriction on publication data)}

[Find Studies, https://www.clinicaltrials.gov/ct2/search]

("oral surgery" OR dental OR tooth OR periodontal) AND (anticoagulant OR anticoagulation OR "vitamin k antagonist" OR VKA OR NOAC OR DOAC) AND (antifibrinolytic OR tranexamic OR cyclokapron OR eaca OR "aminocaproic acid" OR amicar OR TXA)

\section{WHO ICTRP}

[ICTRP Search Portal, http://apps.who.int/trialsearch/]

(oral surgery OR oral surgical procedures OR dental OR tooth OR operative dentistry OR molar OR dentoalveolar OR orthognathic OR periodontal) AND (anticoagulants OR anticoagulant OR anticoagulation OR anticoagulated OR vitamin $k$ antagonist OR anti-vitamin $k$ OR antivitamin k OR anti vitamin k OR VKA OR warfarin OR phenprocoumon OR acenocoumarol OR coumadin OR coumadins OR coumarin OR coumarins OR "new oral anticoagulant" OR "newer oral anticoagulant" OR NOAC OR "non-vitamin k antagonist" OR "non-vitamin-kantagonist" OR "non-vitamin k dependent antagonist" OR DOAC OR "direct oral anticoagulant") AND (antifibrinolytic OR tranexamic OR cyclokapron OR cyklokapron OR eaca OR aminocaproic acid OR amicar OR TXA)

\section{Appendix 2. Additional searches}

\section{American College of Clinical Pharmacy (ACCP) Annual Meeting}

("oral surgery" OR dental OR tooth OR periodontal) AND (anticoagulant OR anticoagulation OR "vitamin k antagonist" OR VKA OR "new oral anticoagulant" OR NOAC OR "direct oral anticoagulant" OR DOAC) AND (antifibrinolytic OR tranexamic OR cyclokapron OR cyklokapron OR eaca OR "aminocaproic acid" OR amicar OR TXA)

Antifibrinolytic therapy for preventing oral bleeding in people on anticoagulants undergoing minor oral surgery or dental extractions 
Annual Scientific Meeting of the International Society for Thrombosis and Haemostasis

("oral surgery" OR dental) AND (anticoagulant OR VKA OR NOAC OR DOAC) AND (antifibrinolytic OR tranexamic OR eaca)

\section{European Haematology Association Annual Congress}

(oral surgery OR dental OR tooth OR molar OR dentoalveolar OR orthognathic OR periodontal) AND (anticoagulant OR anticoagulation OR vitamin $k$ antagonist OR VKA OR warfarin OR phenprocoumon OR acenocoumarol OR Coumadin OR coumarin OR "new oral anticoagulant" OR NOAC OR "direct oral anticoagulant" OR DOAC) AND (antifibrinolytic OR tranexamic OR cyclokapron OR cyklokapron OR eaca OR aminocaproic acid OR amicar OR TXA)

\section{American Society of Hematology Annual Meeting}

(oral surgery OR dental OR tooth OR molar OR dentoalveolar OR orthognathic OR periodontal) AND (anticoagulant OR anticoagulation OR vitamin $k$ antagonist OR VKA OR warfarin OR phenprocoumon OR acenocoumarol OR Coumadin OR coumarin OR new anticoagulant OR NOAC OR direct anticoagulant OR DOAC) AND (antifibrinolytic OR tranexamic OR cyclokapron OR cyklokapron OR eaca OR aminocaproic acid OR amicar OR TXA)

\section{British Society for Haematology Annual Scientific Meeting}

('oral surgery' OR dental) AND (anticoagulant OR VKA OR NOAC OR DOAC) AND (antifibrinolytic OR tranexamic OR eaca)

\section{CONTRIBUTIONS OF AUTHORS}

ET Engelen: designing search strategies en undertaking searches. Screening of search results and of retrieved papers against eligibility criteria. Data collection, extraction and critical appraisal. Data analysis and interpretation. Writing of the review.

REG Schutgens: supervising of the review, securing funding. Verifying the data extraction of trials identified for inclusion.

RJJ van Es: interpretation of data, providing a clinical perspective and general advice on the review.

EP Mauser-Bunschoten: interpretation of data, providing a methodological, clinical, consumer and policy perspective.

KPM van Galen: guarantor of the review, conceiving, designing, coordinating and writing of the review, data collection, extraction and critical appraisal. Screening of search results and of retrieved papers against eligibility criteria. Data analysis and interpretation.

\section{DECLARATIONSOF INTEREST}

There are no potential conflicts of interest for any of the authors. None of the authors have been involved in any of the included trials potentially eligible for inclusion in the review.

\section{SOURCES OF SUPPORT}

\section{Internal sources}

- No sources of support supplied

\section{External sources}

- National Institute for Health Research, UK.

This systematic review was supported by the National Institute for Health Research, via Cochrane Infrastructure funding to the Cochrane Cystic Fibrosis and Genetic Disorders Group.

\section{DIFFERENCES BETWEEN PROTOCOLANDREVIEW}

The primary outcome was redefined as 'Number of participants with major postoperative bleeding episodes (defined as postoperative bleeding episodes requiring intervention) to clarify that the number of participants is the intended unit of analysis for this outcome, rather than the number of episodes.

\section{INDEX TERMS}

\section{Medical Subject Headings (MeSH)}

Anticoagulants [administration \& dosage] [ ${ }^{*}$ adverse effects]; Antifibrinolytic Agents [ ${ }^{\star}$ therapeutic use]; Minor Surgical Procedures [ ${ }^{\star}$ adverse effects]; Oral Hemorrhage [chemically induced] [* ${ }^{*}$ prevention \& control]; Oral Surgical Procedures [*adverse effects]; Tooth Extraction [adverse effects]; Tranexamic Acid [*therapeutic use] 


\section{MeSH check words}

Humans; Middle Aged 